\title{
Dynastic human capital, inequality and intergenerational mobility
}

\author{
Adrian Adermon \\ Mikael Lindahl \\ Mårten Palme
}


The Institute for Evaluation of Labour Market and Education Policy (IFAU) is a research institute under the Swedish Ministry of Employment, situated in Uppsala. IFAU's objective is to promote, support and carry out scientific evaluations. The assignment includes: the effects of labour market and educational policies, studies of the functioning of the labour market and the labour market effects of social insurance policies. IFAU shall also disseminate its results so that they become accessible to different interested parties in Sweden and abroad.

Papers published in the Working Paper Series should, according to the IFAU policy, have been discussed at seminars held at IFAU and at least one other academic forum, and have been read by one external and one internal referee. They need not, however, have undergone the standard scrutiny for publication in a scientific journal. The purpose of the Working Paper Series is to provide a factual basis for public policy and the public policy discussion.

More information about IFAU and the institute's publications can be found on the website www.ifau.se

ISSN 1651-1166 


\title{
Dynastic human capital, inequality and intergenerational mobility $^{\mathrm{a}}$
}

\author{
by \\ Adrian Adermon $^{\mathrm{b}}$, Mikael Lindahl ${ }^{\mathrm{c}}$ and Mårten Palme ${ }^{\mathrm{d}}$
}

November 7, 2016

\begin{abstract}
We study the importance of the extended family - or the dynasty - for the persistence in human capital inequality across generations. We use data including the entire Swedish population, linking four generations. This data structure enables us to - in addition to parents, grandparents and great grandparents - identify parents' siblings and cousins, as well as their spouses, and the spouses' siblings. We introduce and estimate a new parameter, which we call the intergenerational transmission of dynastic inequality. This parameter measures the between-dynasty variation in intergenerational transmission of human capital. We use three different measures of human capital: years of schooling, family income and an index of occupational status. Our results show that traditional parent-child estimates miss about half of the persistence across generations estimated by the extended model.
\end{abstract}

Keywords: Intergenerational mobility, extended family, dynasty, human capital JEL-codes: I24, J62

\footnotetext{
${ }^{a}$ We are grateful for comments from Gordon Dahl, Markus Jäntti, Chris Karbownik, Marco Manacorda, Martin Nybom, Kelly Vosters, Olof Åslund and from participants at seminars at the Department of Economics as well as the Department of Statistics at Uppsala University, Helsinki School of Economics, Lund University, University of Copenhagen, University of Gothenburg, IFAU, ESPE, UCLS, the Family and Education workshop in Hawaii in 2015, the CESifo Economics of Education Conference in Munich 2015, ISER Workshop on Family Economics at University of Essex in 2015, the NBER Cohort Studies Meeting in Los Angeles in 2016, the Intergenerational Transmission of Economic Status: Exposure, Heritability and Opportunity conference in Madrid in 2016, the Zurich Workshop in Economics 2016, University of Oslo and Statistics Norway (SSB). Mikael Lindahl is a Royal Swedish Academy of Sciences Research Fellow supported by a grant from the Torsten Söderberg and Ragnar Söderberg Foundations. He also acknowledges financial support from Jan Wallanders and Tom Hedelius Stiftelse, Tore Browaldh Stiftelse and the European Research Council [ERC starting grant 241161]. Mårten Palme gratefully acknowledges financial support from the Swedish Council of Social Research. Adrian Adermon gratefully acknowledges financial support from the Jan Wallander and Tom Hedelius Research Foundation.

${ }^{\mathrm{b}}$ Institute for Evaluation of Labor Market and Education Policy (IFAU), Uppsala University and UCLS. E-mail: Adrian.Adermon@ifau.uu.se.

c Department of Economics, University of Gothenburg, IFAU, IZA, UCLS and CESifo. E-mail: Mikael.Lindahl@economics.gu.se.

d Department of Economics, Stockholm University and IZA. E-mail: Marten.Palme@ne.su.se.
} 


\section{Table of contents}

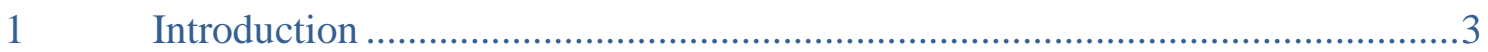

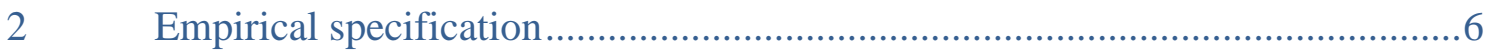

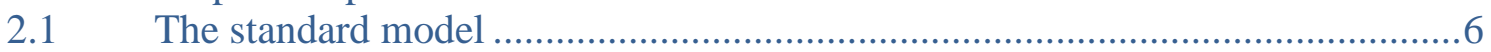

2.2 Model including dynastic human capital.................................................6

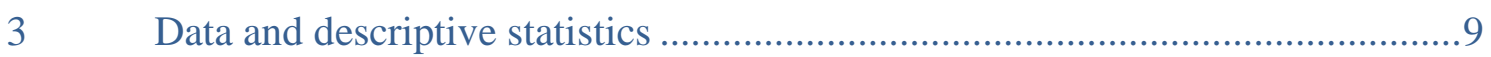

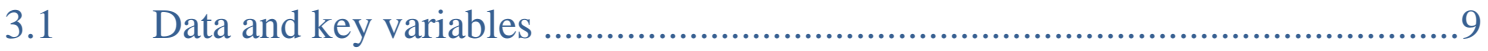

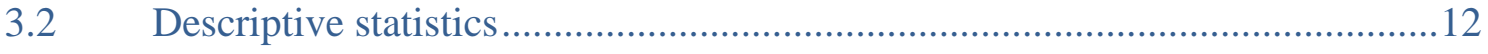

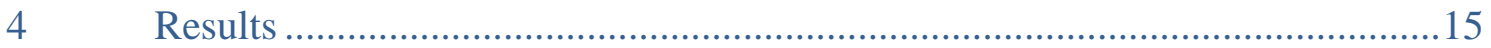

4.1 The Importance of dynastic human capital ........................................................15

4.2 Decomposing the association of the extended family ....................................20

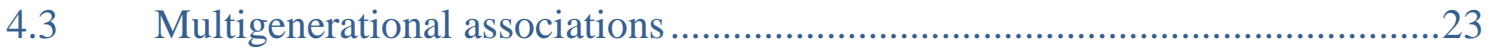

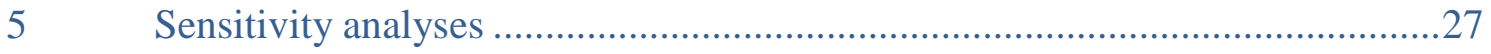

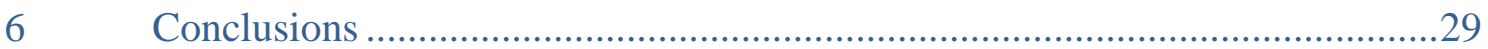

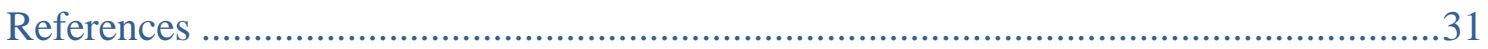

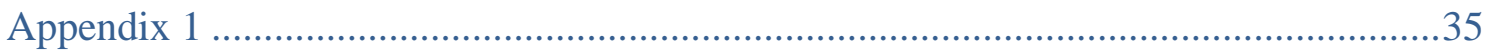

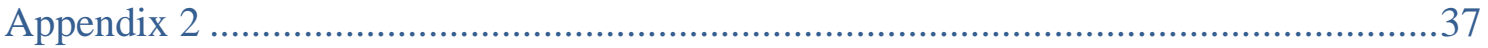




\section{Introduction}

It is well known that group effects are of key importance for how inequality is upheld across generations. Following the social capital theory (see Coleman, 1988) and the strain theory (see Merton, 1938), several studies have shown the importance of social class. There is also a large empirical literature on the importance of race and ethnicity in this context. However, applied work in economics on intergenerational mobility is mostly constrained to the relation between parents and children. A third group of potential importance for an individual's life outcomes is the extended family, or the dynasty, including also more distant relatives than those in the nuclear family.

In this paper, we use a modeling framework inspired by Borjas' ethnic capital model (see Borjas, 1992) for intergenerational mobility, in which he augments the standard parent-child model of intergenerational mobility with an "ethnic capital” variable taking the average outcome in the ethnic group the child belongs to. However, instead of including the average outcome from the individual's ethnic group, we use the outcome from relatives, or "dynastic human capital”. Similarly to Borjas for ethnic background, the argument is that the extended family acts as an externality in the production of human capital of the next generation, which then depends on both parental inputs and the average of the inputs from the members of the extended family in the parental generation, i.e., the siblings, cousins etc. of the parents. The implication is then that if this externality is empirically important, inequality across generations will persist longer, and the convergence between individuals with different human capital backgrounds will be slower than what is predicted from models measuring the association of human capital between children and parents only.

We combine several Swedish registers to match individuals, relatives and spouses using the multigenerational registry and data from several censuses with information on educational attainment, labor earnings, and occupation for the period 1968-2009. We use years of schooling as a measure of educational outcome for about 650,000 individuals in the child generation. The Swedish multi-generation register and the fact that the entire Swedish population is included in the data allow us, for the first time, to link dynasties up to parents' siblings and cousins, the siblings' and cousins' spouses (through marriage and cohabiting records), as well as the siblings of the aunts and uncles. We note that, in principle, the data and this approach make it possible to form 
dynasties of much larger sizes, as long as we allow relatives to be either genetically linked or linked through marriage/cohabitation.

Traditionally, the intergenerational mobility literature is concerned with estimating an intergenerational transmission coefficient that only utilizes variation across parentchild pairs in estimations. Our main contribution is to introduce and estimate a new parameter, the intergenerational transmission of dynastic inequality, which also includes transmissions from the extended family. As such, this parameter captures the betweendynasty variation in intergenerational transmission. This group-based parameter can be decomposed into two parts: the part stemming from parents and the part that comes from the extended family in the parental generation. If the latter parameter is estimated to be positive or if the dynasty-level parameter is estimated to be larger than the traditional parent-child coefficient estimate, we can conclude that the dynastic background slows down intergenerational convergence more than what can be inferred from (misspecified) models that only include parents and children. Since a child can choose neither its parents nor its extended family, the dynasty-level parameter is more relevant than the traditional parent-child parameter for measuring the persistence of inequality.

By using three different indicators of human capital - years of schooling, lifetime family income and an index of occupational-based social stratification - we are able to address the concern that our results are due to measurement error and/or are not capturing the underlying latent variable "human capital” (or "social status") of parents and the dynasty, an issue that has been raised by Clark (2014). Thus, we are able to disentangle the additional persistence due to including information from the extended family and different indicators of human capital, respectively.

Our results strongly suggest that there is additional information in the outcomes from the extended family and that only using parental outcomes when estimating intergenerational mobility severely underestimates the persistence in human capital outcomes across generations. Only considering parental years of schooling in a regression for child years of schooling yields a coefficient estimate of 0.26 . Using the average of the dynastic members' years of schooling in the parental generation increases this estimate by 74 percent to 0.46 . If this model is extended to simultaneously take into account information on schooling, income and social stratification, the estimates increase even 
further by 19 percent to 0.55. Overall, taking extended family human capital into account results in an estimate of intergenerational mobility that is twice as slow as what is suggested by conventional estimates from data including only parents and children.

We are also able to disentangle the effects of dynastic human capital by estimating a multivariate regression model that separately includes indicators from close and/or distant relatives in the parental generation (horizontal influence). When we disentangle the overall extended family effect into categories of relatives in the parental generation, we find that all relatives provide additional information, but that this is especially true for parents' siblings and cousins.

An additional contribution is that we estimate multigenerational models that separately include generations earlier than the parental generation (vertical influence). This relates to a number of recent studies (e.g., Clark, 2014; Lindahl et al., 2015; or Solon, 2015, for an overview) that have shown that grandparents' outcomes have an independent association with a grandchild's outcome, conditional on parents' outcomes. Our very large data set allows us to improve the precision of the estimates substantially compared to those presented in previous studies. By simultaneously incorporating the three proxies, we are, for the first time, able to estimate multigenerational regressions in a latent variable framework. We find that grandparents' human capital is statistically significant in an $\operatorname{AR}(2)$ model using three generations, confirming the results in many recent multigenerational studies using various separate measures. As one of very few papers, we are able to link people across four generations in the same family. We find that great grandparents' human capital is indeed predictive of great grandchildren's schooling. However, conditional on the mediating generations, we find weak associations from great grandparents' income and occupation, and no association from great grandparents' education.

The paper proceeds as follows. In Section 2, we discuss the empirical specifications using the standard and extended models incorporating dynastic capital, also in a latent variable framework. In Section 3, we introduce the data set, discuss the construction of variables, and present some descriptive statistics. In Section 4, we present the results on the importance of dynastic human capital and look at the separate contributions of the dynastic members and the ancestors. In Section 5, we provide some sensitivity analyses. Section 6 concludes the paper. 


\section{Empirical specification}

\subsection{The standard model}

The standard way of measuring how strongly an outcome is transmitted from parents to children is to use the framework of a simple Markovian regression model:

$$
y_{j t}=\alpha+\beta y_{j t-1}+\varepsilon_{j t},
$$

where $y$ represents the outcome under study, $j$ is an index for the immediate family including children $(t)$ and parents $(t-1)$; possibly also controlling for basic characteristics such as birth cohort and gender. For simplicity, we here assume that there is one parent and one child in each immediate family. Assuming that we can measure the outcome perfectly for both generations, the resulting estimate of $\beta$ will be an unbiased measure of the strength of the association between the outcome for parents and children. For instance, if $y$ represents the logarithm of lifetime earnings, an estimate of $\beta$ will be an unbiased estimate of the intergenerational earnings elasticity. If $y$ is standardized to have the same variance, an estimate of $\beta$ can also be interpreted as an intergenerational correlation (see, e.g., Black and Devereux, 2010).

There is a large literature that estimates $\beta$ for different outcomes such as earnings, income, education and social class, using data for many countries and time periods. The key challenge has been to accurately measure the outcome of interest (se e.g. Solon, 1992; Haider and Solon, 2006; Böhlmark and Lindquist, 2006; Nybom and Stuhler, 2016). Measurement error "free” estimates for $\beta$ typically range between 0.2 and 0.6 for lifetime earnings and years of schooling, depending on the outcome studied and the country of origin of the data set used in the study.

\subsection{Model including dynastic human capital}

If the outcomes for the dynastic members outside the immediate family are important for a child's success - i.e., if there exist positive group effects from members of the extended family - a random individual born into a high income family is more likely to have superior outcomes than what can be inferred from an estimate of equation (1). Hence, if the extended family is important, equation (1) is miss-specified. Reinterpreting Borjas' ethnic capital model yields the following simple extension of equation (1):

$$
y_{j d t}=\alpha^{\prime}+\beta^{\prime} y_{j d t-1}+\delta \bar{y}_{d t-1}+\varepsilon^{\prime}{ }_{j d t},
$$


where $d$ is a sub-index for dynasty and $\bar{y}_{d t-1}$ is an average of $y_{j d t-1}$ over the members of the dynasty in the parents' generation (parents, siblings of parents, cousins of parents etc). ${ }^{1}$

Averaging equation (2) over the members in each dynasty $d$, we get:

$$
\bar{y}_{d t}=\alpha^{\prime}+\left(\beta^{\prime}+\delta\right) \bar{y}_{d t-1}+\bar{\varepsilon}_{d t}^{\prime},
$$

or

$$
\bar{y}_{d t}=\alpha^{\prime}+\gamma \bar{y}_{d t-1}+\bar{\varepsilon}_{d t}^{\prime} .
$$

If we estimate (3), and use weights equal to the number of dynasty members, we would get an identical result as if we estimate

$$
y_{j d t}=\alpha^{\prime}+\gamma \bar{y}_{d t-1}+\varepsilon^{\prime}{ }_{j t}
$$

at the immediate family level. In the empirical analysis, we estimate equations (1), (2) and (3’) by Weighted Least Squares, where we weight each dynasty equally (irrespective of the number of children in the dynasty).

The $\beta$ parameter in equation (1) captures the intergenerational persistence in inequality between immediate families $(j)$ whereas $\gamma$ in equation (3) captures the intergenerational persistence in inequality between dynasties $(d)$, where the latter parameter can be decomposed as the sum of the parts transmitted from parents and the extended family, respectively. Note also that estimating equations (3) and (3’) directly is equivalent to regressing equation (1) using a full set of dynasty fixed effects as instruments for $y_{j d t-1}$, highlighting that these equations only utilize between-dynasty variation in $y_{j d t-1} .^{2}$

A comparison between the coefficients in equations (1) and (3) can be thought of in the following way. If the years of schooling of the dynasty are on average one year higher (compared to the average for other individuals), $\gamma$ captures the difference in the predicted value of the child's years of schooling for children in that dynasty, as compared to children in other dynasties. The $\beta$ parameter captures the difference in the predicted value of the child's years of schooling for the children of the parents belonging to that immediate family, as compared to children in other families. Since

\footnotetext{
${ }^{1}$ When we later calculate dynasty averages from the data and estimate equation (2), we do not include the parent among the dynastic members for whom we calculate the dynastic average. Hence, we would replace $\bar{y}_{d t-1}$ in equation (2) by $\bar{y}_{d_{-j} t-1}$. However, this would still give the same equation (3) as we have now, where $\bar{y}_{d t-1}$ includes the parent and all other dynastic members in the parental generation. Hence, this is of no importance for any of the reasoning laid out in this section.

${ }^{2}$ This general point was first made in Solon (1999) footnote 15.
} 
equation (1) is miss-specified, ignoring other dynastic members than the parents, this prediction will be wrong.

The $\beta$ and $\gamma$ parameters will differ if the outcomes of the members of dynasty $d$ other than the parents are associated with the outcome of the child in dynasty $d$. The magnitude of the difference between $\beta$ and $\gamma$ depends on the importance of withindynasty variation relative to the overall variation in $y_{j d t-1}$. Borjas (1992) shows that estimating (1) by OLS, when the true model is (2), results in plim $\hat{\beta}=\beta^{\prime}+$ $\delta\left(1-k_{w}\right) \leq \beta^{\prime}+\delta=\gamma$, where $0 \leq k_{w} \leq 1$ is the weighted average of the withindynasty variance divided by the overall variance of $y_{i d t-1}$, or the fraction of the overall variation in $y_{i d t-1}$ that is due to within-dynasty variation. ${ }^{3}$ Hence, $\hat{\beta}$ is a lower bound estimate of $\gamma$, where the difference between $\beta$ and $\gamma$ is increasing (decreasing) in the relative degree of within (between) dynasty variation in $y_{j d t-1}$. Only if there is no within-dynasty variation in $y_{j d t-1}$ would $\hat{\beta}$ be an unbiased estimate of $\gamma$.

We also note that it requires stronger assumptions to arrive at consistent estimates separately for $\beta^{\prime}$ and $\delta$ than for $\gamma$. The reason is that if $y_{j d t-1}$ is measured with error, $\beta^{\prime}$ will be biased downwards. Since $y_{j d t-1}$ and $\bar{y}_{d t-1}$ will be positively correlated, $\delta$ will be biased upwards. ${ }^{4}$ This is still the case if the number of dynastic members is very large, i.e., so that the measurement error in $\bar{y}_{d t-1}$ approaches zero. However, if equation (3) is estimated using OLS, the bias in the estimate of $\gamma$ (i.e., the sum of $\beta^{\prime}$ and $\delta$ ) approaches zero in the number of dynastic members over which $\bar{y}_{d t-1}$ is averaged.

We will deal with mismeasured variables in the following ways: First, we use highquality data from Swedish registers to create our variables used in the estimations. Second, we use three different proxies for the human capital of the parental generation: years of schooling, family income and a social stratification index, which complement each other in the aspects of human capital that they capture. These are first used

\footnotetext{
${ }^{3}$ Note that the formula in Borjas (1992, p. 131, the first line after equation 14) is incorrect as the numerator should be divided by the number of individuals, $\mathrm{N}$, so that the numerator is equivalent to

$\sum_{j} w_{j} \frac{1}{N_{j}} \sum_{i}\left(y_{i j t-1}-\bar{y}_{j t-1}\right)^{2}$, where $w_{j}=N_{j} / N$ is the relative size of ethnic group $\mathrm{j}$, so that the numerator represents the group size weighted average of the within-group variance terms. This also means that " $\pi$ ", this within group variation term divided by the overall variance, is now bounded by 1 from above. We thank Andreas Dzemski for pointing this out.

${ }^{4}$ See Borjas (1992, page 141) for the case when the true model is equation (1) but when model (2) is estimated. See also Acemoglu and Angrist (2000) who make this specific point about measurement error as following from their general point that an estimate of $\delta$ in (2) will be nonzero as long as, for whatever reason, an OLS estimate of $\beta$ in (1) differs from an IV estimate of $\beta$, where grouped dummy instruments are used.
} 
separately and then also incorporated using a latent variable framework (see section 4). In Appendix 1, we illustrate how the modeling framework in this section is modified with several proxies for an underlying latent variable and how this relates to the recent work by Clark (2014) who attempted to estimate long-run intergenerational mobility in social status, using surnames to link generations. In this paper, we average over individuals in the dynasty, a group which by definition only includes individuals in the immediate and extended family (instead of using proxies such as surnames or other groupings that are less relevant for our purpose).

If we replace $\bar{y}_{d t-1}$ in equation (2) with dynasty fixed effects, we can interpret $\beta^{\prime}$ as the part of intergenerational transmission that is due to within-dynasty variation. Note that we can then rewrite the formula in Borjas (1992) as plim $\hat{\beta}=\beta^{\prime}+\delta\left(1-k_{w}\right)=$ $\beta^{\prime} k_{w}+\gamma\left(1-k_{w}\right)$, so that the OLS estimate of $\beta$ in (1) can be seen as a weighted average of the within-estimate $\beta^{\prime}$ and the between-estimate $\gamma$, where the weights depends on $k_{w}$, the fraction of the overall variation in $y_{i d t-1}$ that is due to withindynasty variation. ${ }^{5}$ We are, however, unable to include dynasty fixed effects in the empirical analysis, since dynasties overlap. ${ }^{6}$ However, since we will incorporate the three proxies simultaneously in a latent variable framework (both for the parents and the dynasties) when we estimate equation (2), we will likely control for most of the dynasty specific characteristics relevant for the child's schooling. Hence, our estimate of $\beta^{\prime}$ will be close to what we would get in a specification including dynasty fixed effects.

\section{Data and descriptive statistics}

\subsection{Data and key variables}

Our data set is compiled from different Swedish registers using the individual identification number. The Swedish Multi-generation register, covering the full population, enables us to link parents to children for all those children born 1932 or later, provided that the child and the parents have been registered as living in Sweden at some point after 1961. We have linked dynasties up to siblings and cousins of parents, as well as (through marriage and cohabiting records) the siblings' and cousins' spouses, the

\footnotetext{
${ }^{5}$ See Hertz (2008) and Torche and Corvalan (2016).

${ }^{6}$ In Borjas, the dynastic component of equation (2) represents a specification for the ethnic group fixed effect. The closest equivalence here would be to include great-grandparent fixed effects instead of the dynastic average in equation (2). However, as we identify relatives to the parents via both spouses, our dynasties will overlap, which makes it impossible to identify a "clean" dynasty group fixed effect.
} 
spouses of the siblings' spouses as well as their siblings. ${ }^{7}$ In principle, it would be possible to (almost infinitely) extend the size of the dynasties, where individuals are genetically linked and/or linked through assortative mating. In practice, we add additional relatives until they no longer provide any explanatory power.

For the child generation, we use years of schooling as the main outcome variable. It is constructed using information from national educational registers. 8 To maximize the number of dynasty members in the parental generation (by allowing children to be born later than what would be required to directly use completed years of schooling), we predict years of schooling for the individuals that are old enough to have finished compulsory schooling but that are too young to have completed their post compulsory education. This is done by first regressing years of schooling on 9th grade GPA at the end of compulsory school (a variable available since 1988), an indicator for having taken an academic (as opposed to a vocational) high school track, a gender dummy, and year of birth, for those aged 30 and older in 2009. We only use those aged 30 and older to allow individuals plenty of time to finish formal education. Then, we use this regression to predict years of schooling for those aged below 30 and for those (few individuals) with missing information on years of schooling. We use actual years of schooling for those aged 30 and older with non-missing data. This is our main outcome variable for the child generation. The results are essentially the same when we instead use observed 9th grade GPA as the outcome variable (see Appendix 2 Tables A6a-A6f). Using actual years of schooling also gives qualitatively similar results, but a much smaller sample size. The final estimation sample covers close to 650,000 children.

We further compile data from registers (and censuses for earlier years) that contain information on education, income and occupation for the parental and other ancestor generations. The education information is available in the 1970 census and in yearly registers between 1985 and 2009. Income data are drawn from tax registers and are available for the years 1968, 1971, 1973, 1976, 1979, 1982, and every year between 1985 and 2009. Occupation information is available from censuses every fifth year

\footnotetext{
${ }^{7}$ Note that Hällsten (2014) previously has used the Swedish multigenerational registry to link first and second cousins in the child generation.

${ }^{8}$ Both for the child and parental generations, we construct years of schooling as follows: seven for (old) primary school, nine for (new) compulsory schooling, 9.5 for (old) postprimary school (realskola), 11 for short high school, 12 for long high school, 14 for short university, 15.5 for long university and 19 for a PhD. For the child generation we mainly use the latest educational register available, which is for 2009. If education for the individual is missing in 2009, we use 2008, and so forth.
} 
between 1970 and 1990. To be included in the estimations, we therefore also require that at least one parent and one cousin of a parent must have survived and still be working in $1970 .^{9}$

For the parental and other ancestor generations we use, in addition to years of schooling, two outcomes: log family income and the so-called CAMSIS index for occupation-based social stratification. The income measure we use is calculated as the sum of gross labor earnings, income from businesses and unemployment benefits. Average log family income is calculated in the following way: we use income data for all available years for each individual between ages 30-60; we take logs and residualize by adjusting for both birth cohort and income year fixed effects; we then take the average of the residuals (and add the constant) for each individual. Lastly, we take averages among parents (if we only observe one parent, we use that observation).

The Cambridge Social Interaction and Stratification (CAMSIS) measure of social distance uses occupations of spouses to create an index (0-100) of social stratification. The basic idea is that individuals who are similar in terms of social status are more likely to marry each other. ${ }^{10}$ The CAMSIS score is constructed by analyzing a frequency cross-table of husbands' and wives' occupations. This table maps out the space of social distances, and from this, it is possible to locate each occupation along an index of social status or stratification. ${ }^{11}$ While there are many occupation-based social classifications, the CAMSIS scale has two advantages for our purposes - first, unlike categorical classifications of social class schemes (e.g., Erikson et al., 1979), it is continuous; second, unlike the Socio-Economic Index of occupational status (ISEI) and similar measures (Ganzeboom et al., 1992), it does not rely on income or education in

\footnotetext{
${ }^{9}$ This means that we have missing data for some of the other categories of relatives. In the dynastic regressions, we simply average outcomes for the parental generation across non-missing categories. In the decomposition regressions, we impute missing categories by setting them to the average of non-missing observations, and adding indicator variables (one for each category of relatives) that equal one if the observation has been imputed, and zero otherwise. As very few observations for the other categories of relatives are missing, this have very little impact on our estimates.

${ }^{10}$ In essence, the scale is constructed by estimating a log-linear model relating each cell in the cross-table to a set of scores for each occupation, where the scores are chosen to maximize the explanatory power of the model. Cell frequencies will then be higher for combinations of occupations which have similar scores. Note that the CAMSIS scale is based on the Cambridge Scale (Stewart et al. 1973), which used friendship rather than marriage as its basis. It has been shown that the two scales have a similar predictive power for intergenerational mobility, mortality, and political attitudes (Prandy and Lambert 2003).

${ }^{11}$ We use the Swedish CAMSIS scale based on data for 2001-2007 prepared by Erik Bihagen and Paul Lambert, available at http://www.camsis.stir.ac.uk/Data/Sweden90.html.
} 
its construction. Hence, CAMSIS provides independent information beyond that contained in our schooling and income variables. ${ }^{12}$

The main independent variables are constructed by taking averages of non-missing observations within each category of relatives (parents, grandparents, aunts/uncles, etc.). For example, if for one child we observe years of schooling for three of their four grandparents, the grandparental years of schooling variable will be the average of those three, excluding the fourth. To construct the dynastic variables, we then average these group averages in the same way. This ensures that each category of relatives is given the same relative weight in the dynasty variables, regardless of how many individuals we observe in that category. If we instead were to construct the dynasty variables by directly averaging across all relatives, we would implicitly be giving a disproportionately large weight to, e.g., parents' cousins, simply because there are relatively many of these in the average family.

\subsection{Descriptive statistics}

Table 1 shows descriptive statistics for the data set. The first three columns show averages of the number of years of schooling, average residualized log family income and the social stratification index by category in the dynasties. The fourth column shows the average number of observations used for calculating the averages corresponding to the category in the dynasty. In effect, we only require one non-missing observation for each category of relatives for a child to be included in the main regressions. The figures show that we have data on almost all grandparents (on average 3.87 out of 4 ) and about half of the great grandparents (4.12 out of 8). The fifth column shows average birth years and, finally, the last column shows the number of observations we have for each category.

A few things should be noted from Table 1. First, the standard deviation for years of schooling for grandparents is comparable to that of parents whereas it is much lower for great grandparents. The latter is due to the fact that a high fraction (about 85\%) of the individuals in that generation only had primary school education. Therefore, it is very beneficial to be able to measure income and occupation for these individuals, so as to incorporate variation in socioeconomic status across the whole distribution. Second, in

\footnotetext{
${ }^{12}$ Lambert and Bihagen (2014) compare a large set of occupation-based social classifications, showing that most measures tend to be relatively highly correlated with each other, and that CAMSIS performs relatively well in predicting unemployment and health.
} 
the last row, we report summary statistics for the dynasty, which we have defined as consisting of the parents, the parents' siblings, the spouses of the aunts and uncles, parents' cousins, the spouses of parents' cousins and the siblings of the spouses of the aunts and uncles. We show below that extending the dynasty definition further does not add any information. Third, summary statistics for all categories (except the children) are based on averages over various numbers of individuals. Hence, the standard deviations of these averaged variables will be lower. This is what explains the low standard deviation for the dynasty in the last column. ${ }^{13}$

Table 1. Summary statistics

\begin{tabular}{|c|c|c|c|c|c|c|}
\hline & $\begin{array}{r}\text { Years of } \\
\text { Schooling }\end{array}$ & $\begin{array}{r}\text { Log family } \\
\text { Income } \\
\text { (residualized) }\end{array}$ & $\begin{array}{r}\text { Social } \\
\text { Stratification }\end{array}$ & $\begin{array}{r}\text { Observations/ } \\
\text { child }\end{array}$ & $\begin{array}{l}\text { Birth } \\
\text { year }\end{array}$ & Observations \\
\hline \multirow[t]{2}{*}{ Child } & 12.46 & & & & 1988.15 & 647,250 \\
\hline & $(1.40)$ & & & & $(4.76)$ & \\
\hline \multirow[t]{2}{*}{ Parents } & 11.65 & -.04 & 46.95 & 1.99 & 1960.95 & 647,250 \\
\hline & $(1.70)$ & $(.50)$ & $(9.82)$ & $(.07)$ & $(4.70)$ & \\
\hline Parents' & 11.69 & -.06 & 46.74 & 4.51 & 1960.98 & 647,250 \\
\hline siblings & $(1.46)$ & $(.41)$ & $(8.48)$ & $(2.34)$ & $(4.76)$ & \\
\hline Spouses of & 11.82 & -.01 & 47.32 & 3.73 & 1961.24 & 639,303 \\
\hline aunts/uncles & $(1.53)$ & $(.40)$ & $(9.01)$ & $(2.04)$ & (6.39) & \\
\hline Spouses of & 12.20 & .02 & 46.17 & 7.73 & 1966.45 & 640,477 \\
\hline parents' cousins & $(1.25)$ & $(.34)$ & $(7.69)$ & $(5.94)$ & (4.29) & \\
\hline Siblings of & 11.72 & -.05 & 47.35 & 7.74 & 1960.82 & 629,507 \\
\hline spouses of aunts/uncles & $(1.40)$ & $(.37)$ & (7.63) & (5.65) & (7.32) & \\
\hline Parents' & 12.17 & -.02 & 46.01 & 10.20 & 1967.92 & 647,250 \\
\hline cousins & $(1.20)$ & $(.35)$ & (7.29) & (7.67) & (4.06) & \\
\hline \multirow[t]{2}{*}{ Grandparents } & 9.29 & -.15 & 45.85 & 3.87 & 1934.20 & 647,233 \\
\hline & $(1.72)$ & $(.38)$ & (7.74) & $(.43)$ & (5.81) & \\
\hline Great & 7.33 & -.20 & 40.92 & 4.12 & 1908.57 & 645,109 \\
\hline grandparents & $(.80)$ & (.63) & $(8.62)$ & $(2.01)$ & (5.81) & \\
\hline Parents' & 9.92 & -.14 & 46.89 & 5.22 & 1942.16 & 646,995 \\
\hline aunts/uncles & $(1.84)$ & $(.40)$ & (8.26) & (3.67) & (4.29) & \\
\hline \multirow[t]{2}{*}{ Dynasty } & 11.88 & -.03 & 46.76 & & 1963.07 & 647,250 \\
\hline & $(.92)$ & $(.21)$ & (4.63) & & (3.76) & \\
\hline
\end{tabular}

Means with standard deviations in parentheses. Observations/child shows the average number of non-missing observations of years of schooling within each category of relatives.

\footnotetext{
${ }^{13}$ Note also that the means for the residualized income variable are negative because individuals differ in the number of years for which they have available income data and because those with fewer years of income data have a lower income.
} 
Table 2 shows correlations between the three main variables years of schooling, log family income and the social stratification index. In Panel A, where we use the parent as the unit of observation, we observe the highest correlation between years of schooling and social stratification, whereas the two correlations with log income are smaller. Although these three variables clearly contain common information, they certainly also capture different things. In Panel B, where we use the dynasty as the unit of observation, the pattern is similar although all three correlations increase.

Table 2. Correlation matrices for the three different measures of parental and dynastic human capital: Years of Schooling, Income and Occupational Status Index

\begin{tabular}{|c|c|c|c|}
\hline & Years of schooling & Log family income & Social stratification \\
\hline & \multicolumn{3}{|c|}{ Panel A: Parents } \\
\hline Years of schooling & 1 & & \\
\hline Log family income & .300 & 1 & \\
\hline \multirow[t]{2}{*}{ Social stratification } & .521 & .306 & 1 \\
\hline & \multicolumn{3}{|c|}{ Panel B: Dynasties } \\
\hline Years of schooling & 1 & & \\
\hline Log family income & .464 & 1 & \\
\hline Social stratification & .632 & .420 & 1 \\
\hline
\end{tabular}

Note: Panel A shows the correlation matrix between years of schooling, lifetime incomes, and social stratification measures, averaged across parents. Panel B shows the corresponding correlation matrix for averages over parents, uncles and aunts, spouses of aunts/uncles, and parents' cousins, spouses of parents' cousins and siblings of the spouses of aunts/uncles.

It has been common in recent work to transform variables used in intergenerational estimations into percentile ranks (Chetty et al., 2015). This has been shown to work well in situations when researchers are forced to use income data not available at mid-life for individuals (Nybom and Stuhler, 2016). Naturally, some other standardization would also be possible, and even though income is not the main variable (and we have lifetime incomes for the parental generation), reporting rank-rank correlations would be informative and rank would also be one way of scaling the three parental variables on the same scale. However, since we will compare estimates where the dependent variable is disaggregated and the dependent variable is aggregated (at the dynastic level) with estimates using only disaggregated variables, reporting estimates using standardized variables can be misleading. ${ }^{14}$

\footnotetext{
${ }^{14}$ The solution would be to standardize the dependent and independent variables at the same level, and then compare the resulting estimates. However, in our setting, this is rather complicated since dynasties overlap (see footnote 4).
} 


\section{$4 \quad$ Results}

\subsection{The Importance of dynastic human capital}

Table 3 shows the first set of results. As for all results shown in this paper, the dependent variable is years of schooling for the individual in the child generation. The table contains three panels. Panel A shows the results when we use years of schooling in the independent variables; Panel B when we use family income; and Panel C when we use the social stratification index. Each panel shows the results from the same specifications. The estimates shown in the first column correspond to Equation (1), which is the traditional specification for the estimation of the parent-child transmission coefficient. The results in the second column correspond to Equation (3'), which is for the estimation of the dynasty-child transmission coefficient, i.e. the transmission of dynastic inequality across generations. The results in the last two columns are from estimations of equations (3') and (2), where, following the convention in the estimation of group effects, we have excluded the child's parents from the calculation of the dynasty’s educational attainments. ${ }^{15}$ We always report robust standard errors. ${ }^{16}$

The first column in Panel A shows that one year of additional parental education is reflected in 0.26 extra years of schooling for the child. This result is very similar to what has typically been obtained in previous studies on Swedish data (see e.g. Björklund et al., 2006). Turning to the second column, we see that an additional year of schooling for the average of the dynasty is associated with 0.46 extra years of schooling for the child. ${ }^{17}$ Comparing the result in the first column with that in the second, following the discussion of Equations (1) and (3'), we can reject that schooling within the dynasty, in addition to the parents, has no effect on the child's educational attainments. This is confirmed by the results in the third column - where we estimate the separate group effect from the dynasty educational attainments - and in the fourth column, where we include both independent variables.

\footnotetext{
${ }^{15}$ Although we do report the $\mathrm{R}^{2}$, s from the various specifications, it should be noted that these are not comparable across specifications, since the independent variables are defined at different aggregation levels. We always use individual variation for the dependent variable whereas we use varying aggregation levels for the independent variables. Hence, although the parameter estimate might increase, the $\mathrm{R}^{2}$ might not, as the fraction of explained variation in the outcome variable decreases with the aggregation level (since only between group variation is then used). Hence, comparisons of the $\mathrm{R}^{2}$ 's across columns are uninformative.

${ }^{16}$ However, even though the errors are likely to be correlated within dynasties we do not report cluster-robust standard errors because dynasties overlap (se Footnote 1). Since we have the population of individuals, and the clusters are relatively small, imposing various cluster definitions is of very little importance for the precision of our estimates.

${ }^{17}$ In Appendix Figures A1a and A1b, we show that the associations in the first and second columns in Panel A of Table 3 are well approximated by a linear specification across the distributions, except in the extreme tails.
} 
Table 3. Results from OLS regressions of the child's predicted years of schooling on three different measures of parental and dynastic human capital: Years of Schooling, Income and Occupational Status Index

\begin{tabular}{|c|c|c|c|c|}
\hline & $(1)$ & $(2)$ & (3) & (4) \\
\hline & \multicolumn{4}{|c|}{ Panel A: Years of schooling } \\
\hline \multirow[t]{2}{*}{ Parents' schooling } & .264 & & & .221 \\
\hline & $(.001)$ & & & $(.001)$ \\
\hline \multirow[t]{2}{*}{ Dynasty schooling } & & .459 & & \\
\hline & & $(.002)$ & & \\
\hline \multirow[t]{2}{*}{ Dynasty schooling, excl parents } & & & .371 & .189 \\
\hline & & & $(.002)$ & $(.002)$ \\
\hline \multirow[t]{2}{*}{$R^{2}$} & .145 & .131 & .101 & .157 \\
\hline & \multicolumn{4}{|c|}{ Panel B: Income } \\
\hline \multirow[t]{2}{*}{ Parents' income } & .643 & & & .568 \\
\hline & $(.003)$ & & & $(.004)$ \\
\hline \multirow[t]{2}{*}{ Dynasty income } & & 1.474 & & \\
\hline & & $(.008)$ & & \\
\hline \multirow[t]{2}{*}{ Dynasty income, excl parents } & & & 1.056 & .723 \\
\hline & & & $(.008)$ & $(.008)$ \\
\hline \multirow[t]{2}{*}{$R^{2}$} & .100 & .097 & .073 & .111 \\
\hline & \multicolumn{4}{|c|}{ Panel C: Occupational status } \\
\hline \multirow[t]{2}{*}{ Parents' occupation } & .036 & & & .031 \\
\hline & $(.000)$ & & & $(.000)$ \\
\hline \multirow[t]{2}{*}{ Dynasty occupation } & & .075 & & \\
\hline & & $(.000)$ & & \\
\hline \multirow[t]{2}{*}{ Dynasty occupation, excl parents } & & & .057 & .037 \\
\hline & & & $(.000)$ & $(.000)$ \\
\hline$R^{2}$ & .108 & .106 & .082 & .122 \\
\hline$N$ & 647,250 & 647,250 & 647,250 & 647,250 \\
\hline
\end{tabular}

Note: The dependent variable is the child's years of schooling for those aged at least 30, and predicted years of schooling based on 9th grade GPA and high school track for those aged below 30. Parental variables are averages across parents, while dynasty variables are averages over parents, parents' siblings, spouses of aunts/uncles, parents' cousins, spouses of parents' cousins, and siblings of spouses of aunts/uncles. All regressions include linear and quadratic controls for average years of birth for each included type of relative. Robust standard errors in parentheses.

By comparing the results in columns 1 and 2 of Panel A, one can get an estimate of the magnitude of the downward bias in the persistence of inequality in years of schooling across generations induced by ignoring the dynasty effects. This comparison suggests that we underestimate the effect by 42 percent. This is very similar to the share of the sum of the coefficients in column 4, which suggests that 46 percent can be attributed to the dynasty. Hence, dynastic human capital appears to be only slightly less important than parents' human capital.

The results for income and occupational status, shown in Panels B and C, respectively, are qualitatively the same as those for education shown in Panel A. However, the magnitude of the share attributed to the dynasty is somewhat larger for both outcomes. 
The estimates for income suggest that about 56 percent of the persistence can be attributed to the dynasty, whereas the number for occupation is 52 percent.

Hence, for all outcomes, a large part, between 45 and 56 percent, of the overall dynastic relationship is due to the extended family. However, as mentioned in section 2.2, it is likely that the attenuation bias due to measurement error in parents' outcomes leads to overestimates of the fraction assigned to the extended family. To look more closely into this issue, we now turn to models where we incorporate the three human capital proxies simultaneously.

Table 4, Panel A, shows the results when we add years of schooling, log family incomes and the index for occupational social stratification to the same specification. In the upper panel, we see that all measures are always statistically significantly associated with the child's years of schooling. Hence, the schooling, income and social stratification measures, for parents and other dynasty members, all provide independent information on the number of years of schooling of the next generation.

The three measures, years of schooling, log family incomes and the index for occupational social stratification, might be viewed as proxies for one underlying latent variable, which we call "human capital”. If so, we would like to combine these variables in some way so as to estimate the parameter capturing the transmission of inequality of dynastic "human capital”. There are various ways of incorporating multiple proxies for an underlying latent variable. One approach is simply to take the average of the standardized variables. This weights the contribution of each variable equally. However, Lubotsky and Wittenberg (2006) (LW) show that a more efficient approach is to obtain a measure as a weighted sum of the separate coefficients, using weights corresponding to the contribution of the variables in explaining the variation in the dependent variable. $^{18}$

\footnotetext{
${ }^{18}$ We can view the three outcome measures as a set of proxy variables for a single latent variable that is transmitted across generations. The true model that we want to estimate is $q=b x+e$, where $\mathrm{q}$ is the outcome variable (here: the child's years of schooling). The latent variable $\mathrm{x}$ is only observed through a set of $\mathrm{H}$ proxy variables, i.e., $y_{h}=\rho_{h} x+$ $u_{h}$, where $\mathrm{h}=1,2 \ldots \ldots \mathrm{H}$. Lubotsky and Wittenberg (2006) show that the most efficient way of using the information in the proxies is to estimate the regression $q=\sum_{h=1}^{H} \varphi_{h} y_{h}+v$, and then take the weighted average $\beta^{*}=$ $\sum_{h=1}^{H} \frac{\operatorname{cov}\left(q, y_{h}\right)}{\operatorname{cov}\left(q, y_{1}\right)} \varphi_{h}$ which is used as an estimate of $b$. Note that for $y_{1}$, which can be any of the proxy variables, we need to normalize and set $\rho_{1}=1$. We always use schooling as $y_{1}$, so that all weighted average coefficients can be interpreted relative to the coefficient on schooling. When we have several categories of relatives in the regression, we always set $\rho=1$ for schooling for each relative. Note that the key assumption is that each $y_{h}$ has no impact on $q$, conditional on $x$.
} 
Table 4. Results from OLS regressions of the child's predicted years of schooling on parent and dynasty schooling, income and the social stratification index for occupational status

\begin{tabular}{|c|c|c|c|c|}
\hline & (1) & (2) & (3) & (4) \\
\hline \multirow[t]{2}{*}{ Parents' schooling } & .193 & & & .166 \\
\hline & $(.001)$ & & & $(.001)$ \\
\hline \multirow[t]{2}{*}{ Parents' income } & .392 & & & .358 \\
\hline & $(.003)$ & & & $(.003)$ \\
\hline \multirow[t]{2}{*}{ Parents' occupation } & .013 & & & .011 \\
\hline & $(.000)$ & & & $(.000)$ \\
\hline \multirow[t]{2}{*}{ Dynasty schooling } & & .317 & & \\
\hline & & $(.003)$ & & \\
\hline \multirow[t]{2}{*}{ Dynasty income } & & .710 & & \\
\hline & & $(.009)$ & & \\
\hline \multirow[t]{2}{*}{ Dynasty occupation } & & .019 & & \\
\hline & & $(.000)$ & & \\
\hline \multirow[t]{2}{*}{ Dynasty schooling, excl parents } & & & .277 & .115 \\
\hline & & & $(.003)$ & $(.003)$ \\
\hline \multirow[t]{2}{*}{ Dynasty income, excl parents } & & & .438 & .224 \\
\hline & & & $(.009)$ & $(.009)$ \\
\hline \multirow{2}{*}{ Dynasty occupation, excl parents } & & & .015 & .005 \\
\hline & & & $(.000)$ & $(.000)$ \\
\hline \multirow[t]{2}{*}{ Parents } & .344 & & & .299 \\
\hline & $(.001)$ & & & $(.001)$ \\
\hline \multirow[t]{2}{*}{ Dynasty } & & .547 & & \\
\hline & & $(.002)$ & & \\
\hline \multirow[t]{2}{*}{ Dynasty, excl parents } & & & .425 & .179 \\
\hline & & & $(.002)$ & $(.002)$ \\
\hline$R^{2}$ & .172 & .144 & .106 & .181 \\
\hline$N$ & 647,250 & 647,250 & 647,250 & 647,250 \\
\hline
\end{tabular}

Note: The dependent variable is the child's years of schooling for those aged at least 30, and predicted years of schooling based on 9th grade GPA and high school track for those aged below 30. Parental variables are averages across parents, while dynasty variables are averages over parents, parents' siblings, spouses of aunts/uncles, parents' cousins, spouses of parents' cousins, and siblings of spouses of aunts/uncles. The lower panel shows Lubotsky \& Wittenberg-type weighted sums of the coefficients in the upper panel, normalized to be comparable to the schooling coefficients. All regressions include linear and quadratic controls for average years of birth for each included type of relative. Robust standard errors in parentheses.

In our setting, we can obtain LW estimates by simply reweighting the estimates in Panel A of Table $4 .{ }^{19}$ We also need to normalize the influence of one of the proxy variables, so that the resulting LW-estimate is interpretable as the effect of a one-unit change in one of the proxies on the dependent variable. As we want to combine these various measures into estimates that are comparable to the main years of schooling estimates,

\footnotetext{
${ }^{19}$ In column 1 of table 4, the LW-weights are 0.219 for income and 5.028 for occupation (the weight for schooling is always 1); in column 2, the weights are 0.189 for income and 4.945 for occupation; in column 3 , the weights are 0.172 for income and 4.865 for occupation; and column 4 uses the column 1 weights for parents and the column 3 weights for the dynasty excluding parents. Note that these weights are multiplied with the coefficient estimates, so that the seemingly large weight for occupation is multiplied with a relatively small coefficient. For example, in column 1 the LW estimate is calculated as $0.193 * 1+0.392 * 0.219+0.013 * 5.028=0.193+0.0858+0.0654=0.344$.
} 
reported in Panel A of Table 3, we always normalize by setting the weight for the schooling variable equal to one. A generalization of this approach is to combine subsets of variables. An example of this is in column 4, where we calculate weighted estimates separately for the parental and the dynastic variables.

The lower panel of Table 4 shows the resulting LW estimates. From the results, it is evident that adding income and social stratification significantly contributes to the estimated persistence. Comparing the estimate for parents in column 1 of the lower panel, with the main estimate in panel A of Table 3, we see that the estimate increases from 0.26 to 0.34 , i.e., by 30 percent. This increase is likely to be driven both by classical measurement errors in years of schooling and by years of schooling being an imperfect proxy for human capital. ${ }^{20}$

If we turn to the estimate for the dynasty in column 2 of the lower panels, we see that it increases from 0.46 to 0.55 , or by 19 percent. In column 4 , we see that this increase is driven by the contribution of the parents, since the dynasty parts (excluding parents) is pretty much unchanged compared to the estimate from only using years of schooling (0.18 versus 0.19 ). The estimate of the part of the overall dynastic relationship due to the extended family is now about $36 \%$. This result supports the claim that bias from measurement error is much more of a problem when estimating the association between outcomes for children and parents, as compared to the association between children and dynasty averages.

In Appendix 2 Table A1, we investigate how sensitive our results are to various definitions of the dynasty. It turns out that the dynasty estimate continues to increase substantially when we successively add members of the extended family to the dynasty average. This is true for schooling, income as well as occupation. For schooling (Panel A of Table 3), the incremental increase from the baseline estimate of 0.26 by adding parents' siblings and their spouses, parents' cousins and their spouses as well as siblings of aunts and uncles is 74 percent. However, if we also add spouses of siblings of spouses of aunts and uncles, the estimate remains almost unchanged. The pattern is very similar for the LW estimates (Panel D of Appendix 2 Table A1). This means that the

\footnotetext{
${ }^{20}$ Nybom and Vosters (2016), for Sweden, and Vosters (2015), for the US, have used the LW approach to estimate the association between the child's income and the parents' income, incorporating influence from parents' education and occupation. They both find a quite small increase from the intergenerational father-son rank correlation in income, as compared to incorporating education and occupation. However, when Nybom and Vosters (2016) incorporate mother's and daughter's income in their analysis, the increase is about $20-30 \%$, which is very much in line with the result in this paper (where the increase is about $30 \%$ ).
} 
dynasty definition we have chosen in our main estimations likely is wide enough to capture the relevant relatives in the extended family.

To conclude, we arrive at a decomposition of the dynasty transmission of inequality in human capital which to about two-thirds (64\%) is due to the parents and about one third to the dynasty. Adding more than one proxy for social status significantly contributes to this large estimated persistence across generations. If we compare the standard parent-child estimate for years of schooling with the dynasty estimate using three proxies for human capital, the latter is more than twice as large as the former. Overall, a child that is born into a dynasty where the members have on average one additional year of "human capital” will, on average, have just over half a year of additional education.

\subsection{Decomposing the association of the extended family}

In Table 5 we disentangle the importance of different parts of the extended family for the education outcome in the child generation. Column 1 of Panel A shows the results from the first column in Table 3, Panel A, as a reference. Then, we sequentially include controls for schooling of parents' siblings, spouses of aunts/uncles, parents' cousins, spouses of parents' cousins and siblings of spouses of aunts/uncles. In panels B and C, we show LW weighted coefficient estimates, from a regression that in addition to schooling also includes income (Panel B) and income and occupation (Panel C), respectively, as proxy variables for human capital for relatives. 
Table 5. Results from OLS regressions of the child's predicted years of schooling on successively additional components of the dynasties. Schooling, Income and Social Stratification Index

\begin{tabular}{|c|c|c|c|c|c|c|}
\hline & (1) & $(2)$ & (3) & (4) & (5) & (6) \\
\hline & \multicolumn{6}{|c|}{ Panel A: Schooling } \\
\hline \multirow[t]{2}{*}{ Parents } & .264 & .225 & .220 & .214 & .214 & .213 \\
\hline & $(.001)$ & $(.001)$ & $(.001)$ & $(.001)$ & $(.001)$ & $(.001)$ \\
\hline \multirow[t]{2}{*}{ Parents' siblings } & & .103 & .090 & .083 & .083 & .080 \\
\hline & & $(.001)$ & $(.001)$ & $(.001)$ & $(.001)$ & $(.001)$ \\
\hline \multirow[t]{2}{*}{ Spouses of aunts/uncles } & & & .038 & .035 & .035 & .028 \\
\hline & & & $(.001)$ & $(.001)$ & $(.001)$ & $(.001)$ \\
\hline \multirow[t]{2}{*}{ Parents' cousins } & & & & .057 & .052 & .052 \\
\hline & & & & $(.001)$ & $(.002)$ & $(.002)$ \\
\hline \multirow[t]{2}{*}{ Spouses of parents' cousins } & & & & & .010 & .010 \\
\hline & & & & & $(.002)$ & $(.002)$ \\
\hline Siblings of spouses of & & & & & & .021 \\
\hline aunts/uncles & & & & & & $(.001)$ \\
\hline \multirow[t]{2}{*}{ Sum of estimates } & .264 & .328 & .348 & .390 & .394 & .404 \\
\hline & $(.001)$ & $(.001)$ & $(.001)$ & $(.002)$ & $(.002)$ & $(.002)$ \\
\hline \multirow[t]{2}{*}{$R^{2}$} & .145 & .154 & .156 & .158 & .158 & .158 \\
\hline & \multicolumn{6}{|c|}{ Panel B: Schooling and income } \\
\hline \multirow[t]{2}{*}{ Parents } & .322 & .280 & .276 & .270 & .269 & .268 \\
\hline & $(.001)$ & $(.001)$ & $(.001)$ & $(.001)$ & $(.001)$ & $(.001)$ \\
\hline \multirow[t]{2}{*}{ Parents' siblings } & & .108 & .095 & .089 & .089 & .086 \\
\hline & & $(.001)$ & $(.001)$ & $(.002)$ & $(.002)$ & $(.002)$ \\
\hline \multirow[t]{2}{*}{ Spouses of aunts/uncles } & & & .034 & .031 & .031 & .026 \\
\hline & & & $(.001)$ & $(.001)$ & $(.001)$ & $(.001)$ \\
\hline \multirow[t]{2}{*}{ Parents' cousins } & & & & .054 & .050 & .049 \\
\hline & & & & $(.002)$ & $(.002)$ & $(.002)$ \\
\hline \multirow[t]{2}{*}{ Spouses of parents' cousins } & & & & & .009 & .008 \\
\hline & & & & & $(.002)$ & $(.002)$ \\
\hline Siblings of spouses of & & & & & & .018 \\
\hline aunts/uncles & & & & & & $(.001)$ \\
\hline \multirow[t]{2}{*}{ Sum of estimates } & .322 & .388 & .405 & .444 & .448 & .456 \\
\hline & $(.001)$ & $(.001)$ & $(.001)$ & $(.002)$ & $(.002)$ & $(.002)$ \\
\hline$R^{2}$ & .166 & .175 & .176 & .178 & .178 & .179 \\
\hline
\end{tabular}




\begin{tabular}{|c|c|c|c|c|c|c|}
\hline & (1) & (2) & (3) & (4) & (5) & (6) \\
\hline & \multicolumn{6}{|c|}{ Panel C: Schooling, income, and social stratification } \\
\hline \multirow[t]{2}{*}{ Parents } & .344 & .300 & .295 & .289 & .289 & .288 \\
\hline & (.001) & (.001) & (.001) & $(.001)$ & $(.001)$ & $(.001)$ \\
\hline \multirow[t]{2}{*}{ Parents' siblings } & & .107 & .094 & .087 & .087 & .085 \\
\hline & & $(.001)$ & $(.002)$ & $(.002)$ & $(.002)$ & $(.002)$ \\
\hline \multirow{2}{*}{ Spouses of aunts/uncles } & & & .036 & .033 & .033 & .028 \\
\hline & & & (.001) & $(.001)$ & $(.001)$ & $(.002)$ \\
\hline \multirow[t]{2}{*}{ Parents' cousins } & & & & .052 & .048 & .048 \\
\hline & & & & $(.002)$ & $(.002)$ & $(.002)$ \\
\hline \multirow{2}{*}{ Spouses of parents' cousins } & & & & & .007 & .007 \\
\hline & & & & & $(.002)$ & $(.002)$ \\
\hline Siblings of spouses of & & & & & & .015 \\
\hline aunts/uncles & & & & & & $(.002)$ \\
\hline \multirow[t]{2}{*}{ Sum of estimates } & .344 & .407 & .424 & .461 & .465 & .471 \\
\hline & $(.001)$ & $(.001)$ & $(.001)$ & $(.002)$ & $(.002)$ & $(.002)$ \\
\hline$R^{2}$ & .172 & .180 & .181 & .182 & .182 & 183 \\
\hline$N$ & 647,250 & 647,250 & 647,250 & 647,250 & 647,250 & 647,250 \\
\hline
\end{tabular}

Note: The dependent variable is the child's years of schooling for those aged at least 30, and predicted years of schooling based on 9th grade GPA and high school track for those aged below 30. Explanatory variables are average years of schooling, average lifetime incomes, and average social stratification measures for each type of relatives. Panels B and C show Lubotsky \& Wittenberg-type weighted sums, normalized to be comparable to the schooling coefficients. All regressions include linear and quadratic controls for average years of birth for each included type of relative. Robust standard errors in parentheses.

The results shown in Panel A of Table 5 reveal highly significant estimates for all parts of the dynasty. The magnitude of the aunt/uncle coefficient is almost half the size of the estimate for parents, but well above twice as large as the corresponding one for the spouses of aunts and uncles. However, even schooling of the siblings of spouses of aunt/uncles enters statistically significant, conditional on schooling for all the other dynasty categories, with an estimate equal to one-tenth of the one for schooling of parents. We note that controlling for all relatives, the estimate for parents' schooling decreases but is still quite large (0.21). This is similar to the estimate in column 4 of Table 3, where we instead used a dynastic average as independent variable. ${ }^{21}$

Most of the variation in child's schooling due to the extended family appears to be captured by including outcomes for parents and parent's siblings. However, as we see from the sum of the coefficient estimates, an additional year of schooling for the dynasty increasingly adds to the child's years of schooling as we keep adding extended

\footnotetext{
${ }^{21}$ These results can be compared to Jaeger (2012) that used data for the US on almost 17,000 children (the Wisconsin Longitudinal Survey) and regressed models of the child's years of schooling on parents' education, SES and income, as well as aunts' and uncles' educations, SES and income. They found that, conditional on parents' outcomes, only aunts' and uncles' education was statistically significantly associated with the child's years of schooling. The coefficient estimates were less than one-third of those for parents.
} 
family members to the model. The results in Panel A therefore confirm those shown in column 4 of Panel A in Table 3, suggesting that an increase of all the extended family members' years of schooling by one year, on average increases the child's predicted years of schooling by about 0.4 years. $^{22}$

The lower panels of Table 5 show the results when we have used the LubotskyWittenberg method for combining indicators. ${ }^{23}$ The estimates are always interpretable in terms of years of schooling for each relative. We find that the estimate for parental years of schooling (in the first row in each panel) always increases, but that the estimates for years of schooling for other relatives are basically unchanged. This is a likely result since years of schooling is an imperfect proxy, which is partly captured by other relatives.

\subsection{Multigenerational associations}

So far, we have concentrated on the effects of human capital on the horizontal dimension in the parental generation. However, there is a (mostly) recent literature that has analyzed multigenerational associations, i.e., looking at the vertical dimension by adding outcomes of grandparents (and, at times, even great grandparents) to the standard parent-child model. Estimations of such AR(2) (and AR(3)) models have found that grandparents do provide additional information and that the parent-child association gives misleading results as regards long-run social mobility (i.e., a parentchild estimate overestimates the degree of social mobility for descendants to the child), using various outcomes such as schooling, income, occupation, and wealth. ${ }^{24}$

In Table 6, we show results from various multigenerational regressions. From the results in Panel A, we see that grandparents' schooling (column 2) and great grandparents' schooling (column 4) are statistically significantly related to schooling of the child. The estimates are sizeable: an additional year of schooling of grandparents (great grandparents) is, on average, associated with one-seventh (one-tenth) of a year of schooling for children. However, it should be noted that the distribution for years of

\footnotetext{
${ }^{22}$ This is seen at the bottom of Panel A, where we simply calculate the sum of all coefficient estimates. Just over half of this effect $(0.213 / 0.404)$ can be attributed to the change in parents' years of schooling and the rest to other dynasty members in the parental generation. This result is naturally very much in line with what we found in column 4 of Panel A in Table 3, where parents' schooling had a coefficient of 0.22 and dynastic schooling a coefficient of 0.19 , summing to 0.41 , since the dynastic average used in Table 3 was calculated based on the same dynastic categories.

${ }^{23}$ In Online Appendix 2 Tables A2a and A2b we show results for separately focusing on income and occupation.

${ }^{24}$ See Solon, 2015 for a survey. Examples of very recent work include Adermon, Lindahl and Waldenström (2016), Braun and Stuhler (2016), Dribe and Helgertz (2016), Ferrie, Massey and Rothbaum (2016) and Modalsli (2016).
} 
schooling is very right-skewed for the great grandparental generation, making comparisons of the size of the coefficient estimates difficult. If one instead standardizes the estimates (having mean zero; SD one), the child-great grandparental association in column 4 decreases to about 0.06, whereas the child-parent and child-grandparent estimates become slightly larger: 0.32 and $0.12 .^{25}$

In column 2, we see that grandparents' schooling is associated with child's schooling, even conditional on parents' schooling, but that the estimate for parents' schooling only decreases by about $10 \%$ when we control for grandparents' schooling. The results in column 5 show that great-grandparents' education is only marginally significant in the $\mathrm{AR}(3)$ model, even if the precision is very good in this very large sample. However, in the last column, we see that siblings of grandparents' schooling has a statistically significant association with child's schooling, conditional on the other relatives.

A problem with interpreting the estimates in Panel A, and with almost all multigenerational estimates in the literature, is that measurement error can lead to biased estimates of the association from the outcomes for grandparents in the AR(2) model and great grandparents in the AR(3) model. There are two counteracting effects. First, the noise due to measurement error in parents' outcomes could be picked up by grandparents' outcomes and hence leading to overestimation of the contribution from grandparents. On the other hand, measurement errors are likely higher for outcomes based on historical data, and hence, the estimate for the association from an outcome for grandparents might be underestimated.

To handle this potential problem, we also estimate the multigenerational models in a latent variable framework, where we use the three human capital proxies for individuals in each ancestor generation. We add income in panel B and income and occupation in panel C, only showing the resulting LW weighted estimates in these panels. Interestingly, this results in a very similar estimate for grandparents, whereas the estimate for parents increases by almost 35\%, Hence, the estimate for grandparents is only about one-sixth of the size as the estimate for parents in the AR(2) model underlying the estimates shown in column 3 of Panel C.

\footnotetext{
${ }^{25}$ Comparing the standardized estimates to those reported for years of schooling in Lindahl et al. (2015), who used data on four generations for individuals from the city of Malmö, Sweden, the estimates are now much more precisely estimated and smaller, although they support the conclusion that the AR(1) model can be rejected.
} 
If we compare these results to the most general model, including both horizontal and vertical ancestors (Appendix 2 Table A3), we see that grandparents' outcomes do provide some information, even conditional on the outcomes for all other relatives. However, for schooling (column 1) and for human capital (using all proxies simultaneously, column 5), grandparents provide very little additional information, conditional on the outcomes for the other relatives. ${ }^{26}$

\footnotetext{
${ }^{26}$ For instance, the estimate for grandparents decreases from 0.048 (column 5 of Table 6) to 0.014 (column 1 of Online Appendix Table A3) when outcomes for all horizontal ancestors are added.
} 
Table 6. Results from OLS regressions of the child's predicted years of schooling on ancestors schooling, income and position in social stratification index

\begin{tabular}{|c|c|c|c|c|c|c|}
\hline & $(1)$ & $(2)$ & (3) & (4) & (5) & (6) \\
\hline & \multicolumn{6}{|c|}{ Panel A: Schooling } \\
\hline \multirow[t]{2}{*}{ Parents } & .264 & & .241 & & .239 & .237 \\
\hline & $(.001)$ & & $(.001)$ & & $(.001)$ & $(.001)$ \\
\hline \multirow[t]{2}{*}{ Grandparents } & & .146 & .048 & & .048 & .041 \\
\hline & & $(.001)$ & $(.001)$ & & $(.001)$ & $(.001)$ \\
\hline \multirow[t]{2}{*}{ Great grandparents } & & & & .098 & .003 & -.008 \\
\hline & & & & $(.002)$ & $(.002)$ & $(.002)$ \\
\hline \multirow[t]{2}{*}{ Parents' aunts/uncles } & & & & & & .022 \\
\hline & & & & & & $(.001)$ \\
\hline \multirow[t]{2}{*}{ Sum of coefficients } & .264 & .146 & .290 & .098 & .289 & .292 \\
\hline & $(.001)$ & $(.001)$ & $(.001)$ & $(.002)$ & $(.002)$ & $(.002)$ \\
\hline \multirow[t]{2}{*}{$R^{2}$} & .145 & .082 & .150 & .051 & .151 & .151 \\
\hline & \multicolumn{6}{|c|}{ Panel B: Schooling and income } \\
\hline \multirow[t]{2}{*}{ Parents } & .322 & & .299 & & .297 & .294 \\
\hline & $(.001)$ & & $(.001)$ & & $(.001)$ & $(.001)$ \\
\hline \multirow{2}{*}{ Grandparents } & & .178 & .052 & & .051 & .044 \\
\hline & & $(.001)$ & $(.001)$ & & $(.001)$ & $(.001)$ \\
\hline \multirow[t]{2}{*}{ Great grandparents } & & & & .119 & .000 & -.012 \\
\hline & & & & $(.003)$ & $(.003)$ & $(.003)$ \\
\hline \multirow[t]{2}{*}{ Parents' aunts/uncles } & & & & & & .024 \\
\hline & & & & & & $(.001)$ \\
\hline \multirow[t]{2}{*}{ Sum of estimates } & .322 & .178 & .350 & .119 & .348 & .350 \\
\hline & $(.001)$ & $(.001)$ & $(.001)$ & $(.003)$ & $(.003)$ & $(.003)$ \\
\hline \multirow[t]{2}{*}{$R^{2}$} & .166 & .086 & .171 & .051 & .172 & .172 \\
\hline & \multicolumn{6}{|c|}{ Panel C: Schooling, income, and occupation } \\
\hline \multirow[t]{2}{*}{ Parents } & .344 & & .320 & & .318 & .315 \\
\hline & $(.001)$ & & $(.001)$ & & $(.001)$ & $(.001)$ \\
\hline \multirow[t]{2}{*}{ Grandparents } & & .205 & .052 & & .051 & .044 \\
\hline & & $(.001)$ & $(.001)$ & & $(.001)$ & $(.001)$ \\
\hline \multirow[t]{2}{*}{ Great grandparents } & & & & .214 & -.002 & -.021 \\
\hline & & & & $(.005)$ & $(.005)$ & $(.005)$ \\
\hline \multirow[t]{2}{*}{ Parents' aunts/uncles } & & & & & & .024 \\
\hline & & & & & & $(.001)$ \\
\hline \multirow[t]{2}{*}{ Sum of estimates } & .344 & .205 & .371 & .214 & .367 & .362 \\
\hline & $(.001)$ & $(.001)$ & $(.001)$ & $(.005)$ & $(.005)$ & $(.005)$ \\
\hline$R^{2}$ & .172 & .090 & .176 & .052 & .176 & .177 \\
\hline$N$ & 647,250 & 647,250 & 647,250 & 647,250 & 647,250 & 647,250 \\
\hline
\end{tabular}

Note: The dependent variable is the child's years of schooling for those aged at least 30, and predicted years of schooling based on 9th grade GPA and high school track for those aged below 30. Explanatory variables are average years of schooling, average lifetime incomes, and average social stratification measures for each type of relatives. Panels B and C show Lubotsky \& Wittenberg-type weighted sums, normalized to be comparable to the schooling coefficients. All regressions include linear and quadratic controls for average years of birth for each included type of relative. Robust standard errors in parentheses.

In Appendix 2 Tables A4a and A4b, we show results when we use family income and occupation, separately, as measures of ancestors' human capital. An interesting difference compared to what we observed for schooling is that, for both income and 
occupation, there is a positive and statistically significant association between great grandparents and great grandchildren in the AR(3) models. We also see a stronger estimate for grandparents. The background to this difference is likely to be the weakness of the schooling measure for grandparents and great grandparents. Most of these individuals finished their education at a time when quite few people attained schooling levels above primary school. Hence, there is very little variation for a large part of the population, as opposed to the income and occupation measures. However, when we add all these measures simultaneously, as seen in Panel C, using the LW framework (and normalizing the contribution of schooling to be equal to one), the results are fairly similar to when we use the schooling measure only.

One way to compare the results from parent-child (AR(1)) models to those of multigenerational (AR(2)), following Ferrie et al (2016), is to simulate how large an estimate from the (misspecified) AR(1) model would need to be in order to predict the same long-term intergenerational persistence (over 10 generations) as the estimates from the multigenerational model. We use the standardized (to have zero mean and unity standard deviation) estimates shown in column 3 of Panel A in Table 6 for such exercise. ${ }^{27}$ We find that a two-generation model underestimate long-run persistence by 12 percent. Since the corresponding number on US data from Ferrie et al. (2016) is 20 percent, our result suggests that the discrepancy between the results from the AR(1) model and the long-term intergenerational persistence in educational attainments is somewhat larger in the US. ${ }^{28}$

\section{Sensitivity analyses}

The intergenerational persistence estimates of Clark (2014), using dynasties linked with surnames, have been criticized for ignoring the potential effect of neighborhood, race and ethnicity, for which surnames are indicative and would therefore result in an overestimate of true persistence across families (see e.g. Chetty et al., 2014, and Solon,

\footnotetext{
${ }^{27}$ The standard deviations differ slightly from those reported in Table 1 and are here 2.06 (children), 2.22 (parents) and 0.95 (grandparents) for years of schooling. Hence, the standardized estimates in column 3 of Panel A in Table 6 are 0.260 (parents) and 0.022 (grandparents).

${ }^{28}$ There are alternative approaches to infer the degree of long-term intergenerational persistence (Lindahl et al., 2015, and Braun and Stuhler, 2016). However, typically such calculations assume that the true model is AR(1). For instance, if we follow the approach in Lindahl et al. (2015) and use grandparents' schooling as instrument for parents' schooling we get an estimate of 0.476 , which is substantially higher than the child-parent estimate of 0.264 . However, this is most likely an upper bound estimate of the long-term intergenerational persistence as grandparents' schooling most likely is positively related to child's schooling in an AR(2) model.
} 
2014). This is potentially also an issue for our main estimates reported in Table 3 and Table 4.

There are, however, at least two reasons to why we think that this critique is less relevant in our context. First, since we require great-grandparents to be identified in our data, our sample consist of children whose ancestors have been living in Sweden for at least four generations. At that time, Sweden was very ethnically homogenous and it is therefore unlikely that group effects based on race or ethnicity would affect our results. Second, as shown by Lindahl (2012) neighborhoods are of limited importance in explaining variation in outcomes such earnings, schooling and student achievement in Sweden.

Nevertheless, to test if residential location can explain our large dynasty estimates, we add regional fixed effects to the baseline models (1), (2) and (3'). The results of this exercise are shown in Appendix 2 Table A7. Comparing the baseline results in Panel A to those from models including municipality fixed effects (Panel B) and parish fixed effects (Panel C), it is obvious that the baseline results are very robust, suggesting that the main results are not driven by dynasty members growing up in the same regions.

In the main analysis, we use predicted years of schooling for those aged below 30 and for those with missing information on years of schooling. In online Appendix 2 Tables A6a-A6i, we show that the results are essentially the same when we instead use observed 9th grade GPA as the outcome variable. If we use actual years of schooling, and then limit the sample to those aged 30 and older with non-missing data, we get qualitatively similar results, but a much smaller sample size. These results are shown in Appendix 2 Tables A8a-A8i.

Finally, in the estimations so far we only required one representation of each category of the extended family (grandparents, parents' siblings etc). If we require each dynasty to be complete, the results remain similar. ${ }^{29}$ Appendix 2 Table A9a shows the equivalent of Table 6, Panel A. A difference is that the great-grandparents variable is now statistically significant, conditional on parents' and grandparents' years of schooling. This is not surprising since dynasties with observations for all member

\footnotetext{
${ }^{29}$ We restrict the sample to only dynasties that have non-missing observations on both parents, all four grandparents, and all eight great grandparents. Corresponding restrictions on other categories are not feasible, since the number of individuals in these categories is not fixed.
} 
categories are likely to be much younger. Hence, great grandparents are more likely to be alive and to have had a direct influence on great grandchildren's education.

\section{Conclusions}

We obtain two main sets of results. The first one comes from models where we add an additional component measuring the average human capital of the extended family. The estimates suggest that we miss over 40 percent of the persistence when omitting the educational attainment outcomes of the dynasty. If we use income or the social stratification measure, the downward bias is even larger. The most important part of the omitted persistence is attributed to the child's aunts/uncles and the cousins of the parents.

The second set of results come from models where we combine three different human capital outcome measures using the Lubotsky-Wittenberg method for estimating the importance of the latent variable "human capital". This set of results shows that the intergenerational persistence estimate increases from 0.26 to 0.34 (or by 30 percent), when we include income and the social stratification index in addition to educational attainment in the LW procedure. The dynasty persistence estimate increases from 0.46 to 0.55 (an additional 20 percent).

To conclude, the results obtained in this study unambiguously suggest that it is not sufficient to use data on only parents and children, or on only one outcome, when studying intergenerational persistence in human capital. The persistence between extended families across generations is much stronger than what parent-child studies suggest. This has implications for how we interpret persistence in inequality across generations and for the recently suggested interpretation of the difference between siblings estimates and results from parent-child models as the influence of everything that siblings share except their parental background on persistence in human capital outcomes (see e.g. Solon, 1999, or Björklund and Jäntti, 2012).

Our results also speak to an emerging literature based on estimates from multigenerational models. We use the LW approach when we estimate the multigenerational models, allowing for generation-specific latent variables. This results in larger estimates for parents, confirming that measurement error is an issue that understates the importance of parents relative to grandparents in multigenerational models. However, 
assuming that the true intergenerational persistence parameter is well represented by an AR(1) model for the latent variable "social status”, our estimate of intergenerational persistence is substantially lower than the influential estimate in Clark (2014), which, based on intergenerational models using surname-groups, found estimates of intergenerational persistence between 0.7 and 0.8 .

Although our estimates contradict the interpretation by Becker and Tomes (1986) of the evidence at the time of a weak intergenerational persistence of economic advantage and inequality, they support the general message of the Becker-Tomes model of the family as an important engine in the formation of human capital. In fact, we show the importance of a specific type of group effect in this research area, which points to a more important role of family background than what recent studies in have concluded. There are important externalities of human capital formation within the extended family, or the dynasty as we label it. 


\section{References}

Acemoglu, D. and J. Angrist (2000). "How Large Are Human-Capital Externalities? Evidence from Compulsory Schooling Laws.” NBER Macroeconomics Annual, 15, $9-59$.

Adermon, A., M. Lindahl, and D. Waldenström, (2016). "Intergenerational wealth mobility and the role of inheritance: Evidence from multiple generations”. IZA Working paper 10126.

Becker, G. S. and N. Tomes (1979). “An Equilibrium Theory of the Distribution of Income and Intergenerational Mobility”, Journal of Political Economy 87(6), 11531189.

Becker, G. S. and N. Tomes (1986). “Human Capital and the Rise and Fall of Families”, Journal of Labor Economics 4(3), S1-S39.

Björklund, A., and M. Jäntti (2012). "How Important is family background for laboreconomic outcomes”, Labour Economics, 19, 465-474.

Björklund, A., M. Lindahl, and E. Plug (2006). “The Origins of Intergenerational Associations: Lessons from Swedish Adoption Data”, Quarterly Journal of Economics, 121(3), 999-1028.

Black, S. and P. Devereux (2010). "Recent Developments in Intergenerational Mobility”, in Handbook of Labor Economics, vol. 4B, eds. O. Ashenfelter and D. Card, 1487-1541. Amsterdam: Elsevier.

Böhlmark, A., and M. J. Lindquist (2006). "Life-Cycle Variations in the Association between Current and Lifetime Income: Replication and Extension for Sweden”, Journal of Labor Economics 24(4), 879-896.

Borjas, G. J. (1992). "Ethnic Capital and Intergenerational Mobility” The Quarterly Journal of Economics, 107(1), 123-150.

Braun, S. and J. Stuhler (2016). “The Transmission of Inequality Across Multiple Generations: Testing Recent Theories with Evidence from Germany”, forthcoming Economic Journal. 
Chetty, R., N. Hendren, P. Kline and E. Saez (2014). "Where is the Land of Opportunity? The Geography of Intergenerational Mobility in the United States”, Quarterly Journal of Economics 129(4): 1553-1623.

Clark, G. (2014). The Son Also Rises: Surnames and the History of Social Mobility, Princeton, NJ: Princeton University Press.

Clark, G. and N. Cummins (2014) "Intergenerational Wealth Mobility in England, 1958-2012: Surnames and Social Mobility”, Economic Journal, 125(582), 61-85.

Coleman, J. S. (1988): “Social Capital in the Creation of Human Capital”, American Journal of Sociology, 94, pp. S95-S120.

Dribe, M. and J. Helgertz (2016) "The Lasting Impact of Grandfathers Class, occupational status, and earnings over three generations in Sweden 1815-2011”, Journal of Economic History, 76(4), 969-1000.

Erikson, R., J.. Goldthorpe, and L. Portocarero. "Intergenerational Class Mobility in Three Western European Societies: England, France and Sweden.” The British Journal of Sociology 30, no. 4 (1979): 415-41.

Ferrie, J. and J. Long (2015). “Grandfathers Matter(ed): Occupational Mobility Across Three Generations in the U.S. and Britain, 1850-1910.” Working Paper.

Ferrie, J., C. Massey and J. Rothbaum (2016). "Do Grandparents and Great-grandparents Matter? Multigenerational Mobility in the US, 1910-2013”. NBER Working Paper 22635.

Ganzeboom, Harry B. G., Paul M. De Graaf, and Donald J. Treiman. “A Standard International Socio-Economic Index of Occupational Status.” Social Science Research 21, no. 1 (March 1, 1992): 1-56.

Haider, S. and G. Solon (2006). "Life-Cycle Variation in the Association between Current and Lifetime Earnings”, American Economic Review 96(4), 1308-1320.

Hertz, T. (2008). “A Group-specific Measure of Intergenerational Persistence”. Economics Letters 100:415-17. 
Hällsten, M. (2014) “Inequality across three and four generations in Egalitarian Sweden: 1st and 2nd cousin correlations in socio-economic outcomes”, Research in Social Stratification and Mobility 35: 19-33.

Jaeger, M. M. (2012). “The Extended Family and Children's Educational Success”, American Sociological Review 77(6), 903-922.

Lambert, Paul S., and Erik Bihagen. "Using Occupation-Based Social Classifications.” Work, Employment \& Society 28, no. 3 (June 1, 2014): 481-94.

Lindahl, L. (2011). “A comparison of family and neighborhood effects of grades, test scores, educational attainment and income - evidence from Sweden”, Journal of Economic Inequality 9, 207-226.

Lindahl, M., M. Palme, S. Sandgren Massih, and A. Sjögren (2015) "Long-term intergenerational persistence of human capital: an empirical analysis of four generations” Journal of Human Resources 50(1), 1-33.

Long, J. and J. Ferrie (2013). “Intergenerational Occupational Mobility in Great Britain and the United States since 1850”, American Economic Review 103(4), 1109-1137.

Lubotsky, D., \& Wittenberg, M. (2006). “Interpretation of regressions with multiple proxies. The Review of Economics and Statistics, 88(3), 549-562.

Merton, R. K. (1938): “Social Structure and Anomie”, American Sociological Review, 3(5), pp. 672-682.

Modalsli, J. (2016) "Multigenerational Persistence: Evidence from 146 Years of Administrative Data”. Mimeo, Statistics Norway.

Nybom, M., and J. Stuhler (2013). "Interpreting Trends in Intergenerational Income Mobility” Swedish Institute for Social Research Working Paper 3/2014.

Nybom, M., and J. Stuhler. (2016). "Heterogeneous Income Profiles and Life-Cycle Bias in Intergenerational Mobility Estimation”, Journal of Human Resources, Vol. 51(1), 239-268.

Nybom, M., and K. Vosters (2016). "Intergenerational Persistence in Latent Socioeconomic Status: Evidence from Sweden and the United States”, forthcoming in Journal of Labor Economics. 
Prandy, Kenneth, and Paul Lambert. "Marriage, Social Distance and the Social Space: An Alternative Derivation and Validation of the Cambridge Scale.” Sociology 37, no. 3 (August 1, 2003): 397-411.

Solon, G. (1992). “Intergenerational Income Mobility in the United States”, American Economic Review 82 (June), 393-408.

Solon, G.. (1999). “Intergenerational Mobility in the Labor Market”, in: O. Ashenfelter and D. Card (Eds.), Handbook of Labor Economics, Vol. 3. Amsterdam: Elsevier.

Solon, G. (2015). “What Do We Know So Far about Multigenerational Mobility?”, NBER Working Paper 21053.

Stewart, A., K. Prandy, and R. M. Blackburn. "Measuring the Class Structure.” Nature 245, no. 5426 (October 26, 1973): 415-17.

Torche, F. and A. Corvalan (2016). "Estimating Intergenerational Mobility With Grouped Data: A Critique of Clark's the Son Also Rises”, Sociological Methods \& Research, 1-25.

Vosters, K. (2015). "Is the simple Law of Mobility really a law? Testing Clark’s hypothesis”. Mimeo, Michigan State. 


\section{Appendix 1}

\section{Extension to a model allowing for mis-measurement of an underlying latent variable}

To understand the impact of using imperfect proxies of an underlying latent variable on the estimates in a model with a latent variable, we use the simple model laid out in Clark (2014). This simple model of intergenerational transmission says that for family $j$ some outcome $y$ evolves as $y_{j t}=x_{j t}+u_{j t}$ and $x_{j t}=b x_{j t-1}+e_{j t}$, where $x$ is some underlying latent variable such as human capital or (as in Clark 2014) "social status", which evolves as an $\operatorname{AR}(1)$ across generations $(t) ; u$ is a generation-specific error in measuring $x$ (uncorrelated with $x$ and with $u$ for other generations); and $e$ is an idiosyncratic shock, uncorrelated with $u$ and with $x$ in the previous generation. We call $b$ the long-term intergenerational persistence in human capital.

We can use this simple model to illustrate what parameters we are estimating in a situation where we allow for multiple (h) proxies for $x$ and where we recognize that individuals can be grouped into dynasties (d). We can then write the model as:

$$
\begin{aligned}
& y_{h j d t}=\rho_{h} x_{j d t}+u_{h j d t} \\
& x_{j d t}=b x_{j d t-1}+e_{j d t}
\end{aligned}
$$

By adding the coefficient $\rho_{h}$ in the proxy equation (4), we allow each $y$ to vary in their scale and in how well they proxy for $x$. For illustrative purposes, let us normalize and set $\rho_{h}=1$, so that the measurement errors in (4) are classical. In the estimations, we will set $\rho_{1}=1$, but allow for $\rho_{h>1} \neq 1$, where $\mathrm{h}=1$ is the proxy relative to which we interpret $\mathrm{b}$.

A regression of $y_{j d t}$ on $y_{j d t-1}$ (i.e., model (1)), for any of the $h$ proxies, then gives:

$$
\operatorname{plim} \hat{\beta}_{O L S}=\frac{\operatorname{cov}\left(y_{j d t}, y_{j d t-1}\right)}{\operatorname{var}\left(y_{j d t-1}\right)}=b \theta_{h} \leq b
$$

where $\theta_{h}=\frac{\operatorname{var}\left(x_{j d t}\right)}{\operatorname{var}\left(y_{h j d t}\right)}$ assuming that the variances are constant across $t$ 's. This is the standard formula for measurement error bias. ${ }^{30}$ By instead taking averages of $y$ over $h$ in this regression, we have that the variance of the average of $y$ (across $h$ 's) approaches the variance of $x\left(\right.$ since $\operatorname{var}\left(\bar{u}_{j d t}\right)<\operatorname{var}\left(u_{h j d t}\right)$ where we note that now $\left.\theta=\frac{\operatorname{var}\left(x_{j d t}\right)}{\operatorname{var}\left(\bar{y}_{h j d t}\right)}\right)$, so that $\theta \rightarrow 1$ and $\hat{\beta}_{O L S} \rightarrow b$, where $\hat{\beta}_{O L S}$ from the estimation of equation (1) in the paper.

\footnotetext{
${ }^{30}$ Note that if we allow for $\rho_{h} \neq 1$, we get that $\operatorname{plim} \hat{\beta}_{O L S}=\rho_{h}{ }^{2} b \theta_{h}$ which can be greater than b, unless $\rho_{h} \leq 1$.
} 
Clark (2014) argues that by taking group averages (they use surnames) one can eliminate the importance of generation-specific effects because the average of $u_{h j d t}$, for a given $h$, will then approach zero and hence, $\theta \rightarrow 1$. However, as pointed out by Chetty et al. (2014: Online Appendix, p. 9), using averages over any group will estimate the intergenerational persistence between groups, which is a different parameter than the intergenerational persistence between families.

In this paper, we average over individuals in the dynasty, a group which, by definition, only includes individuals in the immediate and extended family (instead of using proxies such as surnames or other groupings that are less relevant for our purpose). We also utilize three different outcomes: educational attainments, earnings and an index of social stratification.

Just like in equation (2), we now extend this model by allowing for individuals in generation $t-1$, other than the parent, to influence the human capital of the child. This gives a modified equation (5) as

$$
x_{j d t}=b^{\prime} x_{j d t-1}+c \bar{x}_{d t-1}+e_{j d t},
$$

which is a hybrid of the model of transmission of ethnic capital between generations in Borjas (1992), adapted to dynastic capital, and the modeling framework in Clark (2014). Taking averages over individuals within dynasties, we can rewrite (4) and (6) as:

$$
\begin{aligned}
& \bar{y}_{h d t}=\rho_{h} \bar{x}_{d t}+\bar{u}_{h d t} \\
& \bar{x}_{d t}=\left(b^{\prime}+c\right) \bar{x}_{d t-1}+\bar{e}_{d t}
\end{aligned}
$$

A regression of $\bar{y}_{d t}$ on $\bar{y}_{d t-1}$ (i.e., equation (3)) for any of the $h$ 's (again normalizing $\rho_{h}$ to one) then gives:

$$
\operatorname{plim} \hat{\gamma}_{O L S}=\frac{\operatorname{cov}\left(\bar{y}_{d t}, \bar{y}_{d t-1}\right)}{\operatorname{var}\left(\bar{y}_{d t-1}\right)}=\left(b^{\prime}+c\right) \theta^{\prime} \leq b^{\prime}+c
$$

where $\theta^{\prime}=\frac{v\left(\bar{x}_{d t}\right)}{v\left(\bar{y}_{d t}\right)}$ assuming that all variances are constant across time.

By taking averages of $y$ over $h$ in this regression, we once more have that $\theta^{\prime} \rightarrow 1$ and that $\hat{\gamma}_{\text {OLS }} \rightarrow b^{\prime}+c$. Note that for small $d, \theta^{\prime}<1$ is likely but that we expect $\theta<\theta^{\prime}$ since we already averaged across dynastic members. 


\section{Appendix 2}

\section{Figures and tables}

We illustrate the relationship in columns 1 and 2 of Panel A of Table 3 in Figure A1 a and Figure A1 b. The figures plot the child's years of schooling against years of schooling for the parents (1a) and the dynasty (1b). Each figure shows a local linear kernel regression fit, a linear regression fit, and a kernel density for the parental/dynasty variable. These figures show the bivariate relation after controlling for the child's cohort dummies and second-order polynomials in birth years for each included category of relative (same as in the regressions). In these plots, the variables are residuals from regressions of the original outcome variables on the relevant controls. Hence, the y-axis shows the child's years of schooling and the x-axis shows parental/dynasty years of schooling residualized with zero mean. The $x$-axis also shows the $5^{\text {th }}$ and the $95^{\text {th }}$ percentile of the observations.

Figure A1 a. The relation between the child's and parents' years of schooling

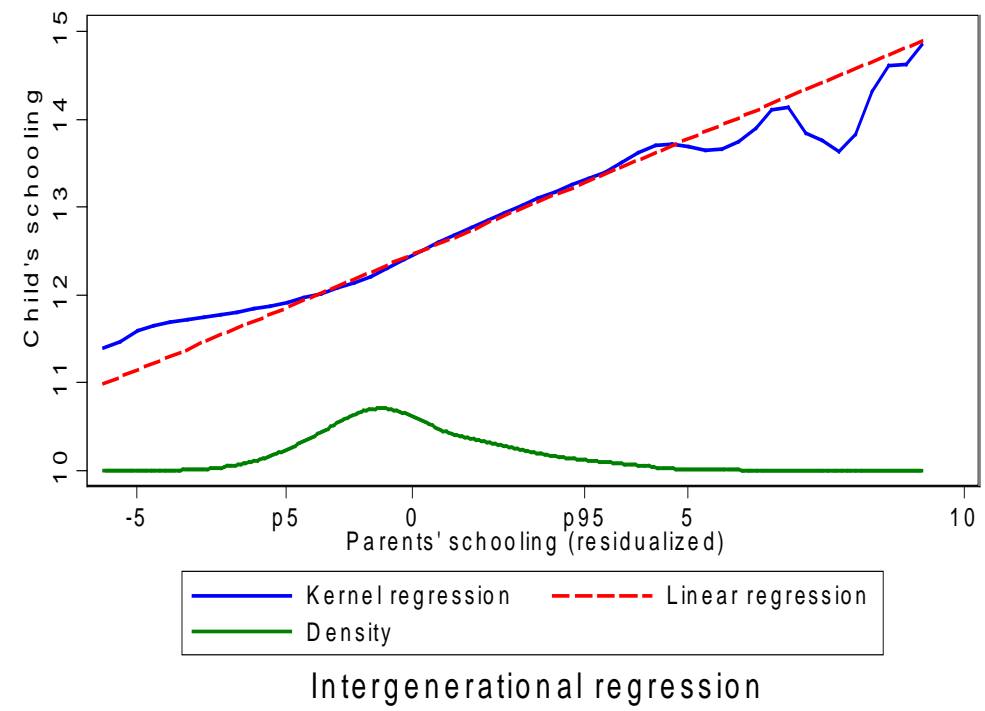

Notes: The horizontal axis shows parents' schooling after regressing out child's birth cohort dummies and a second order polynomial in parents' birth year, and the vertical axis shows child's years of schooling for those aged at least 30, and predicted years of schooling based on 9th grade GPA and high school track for those aged below 30. The 5th and 95th percentiles of residualized parental schooling are labeled as "p5" and "p95" on the horizontal axis. Lines show fitted values from bivariate OLS and kernel regressions, with a kernel density estimate of the distribution of parental schooling. 
Figure A1 b. The relation between the child's and the dynasties' years of schooling

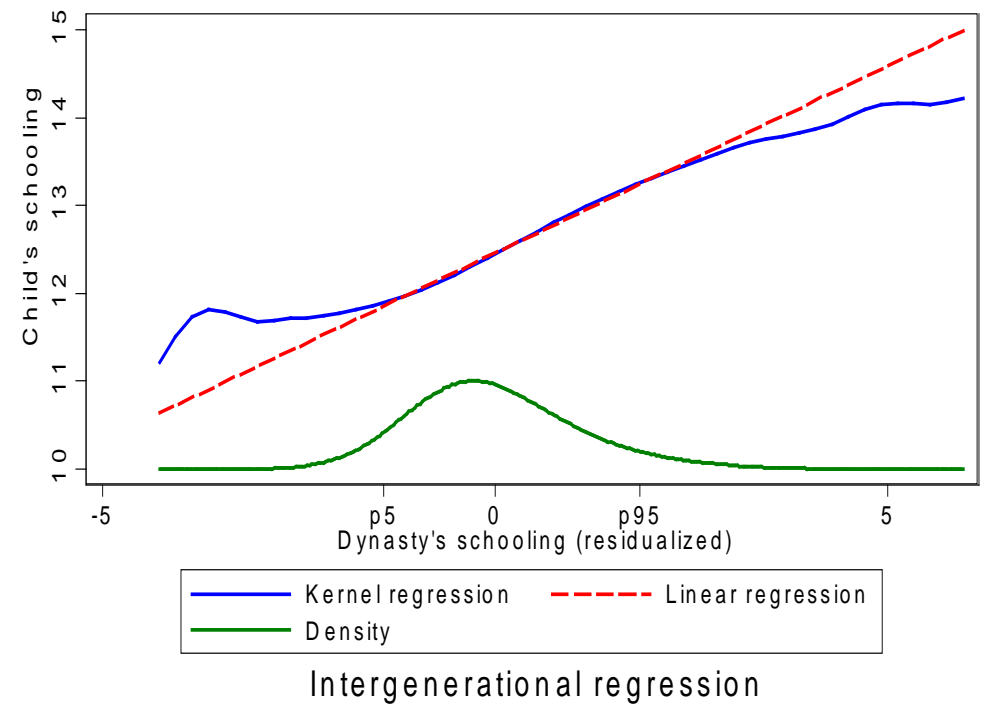

Notes: The horizontal axis shows average dynasty schooling after regressing out child's birth cohort dummies and a second order polynomial in average dynasty birth year, and the vertical axis shows child's years of schooling for those aged at least 30, and predicted years of schooling based on 9th grade GPA and high school track for those aged below 30. The 5th and 95th percentiles of residualized dynasty schooling are labeled as "p5" and "p95" on the horizontal axis. Lines show fitted values from bivariate OLS and kernel regressions, with a kernel density estimate of the distribution of dynasty schooling.

The slope of the dotted lines corresponds to the parameter estimates reported in the first and second columns of Panel A of Table 3. We see that a local linear kernel regression fit is non-linear at the tails of the distributions in both figures but linear between the $5^{\text {th }}$ and $95^{\text {th }}$ percentile. Hence, linearity appears to be a good approximation. 
Table A1. Results from OLS regressions of the child's predicted years of schooling on dynasty schooling. Successively expanding dynasties

\begin{tabular}{|c|c|c|c|c|c|c|}
\hline & (1) & (2) & (3) & (4) & (5) & (6) \\
\hline & \multicolumn{6}{|c|}{ Panel A: Schooling } \\
\hline \multirow[t]{2}{*}{ Dynasty } & .341 & .359 & .426 & .449 & .459 & .455 \\
\hline & $(.001)$ & $(.001)$ & $(.002)$ & $(.002)$ & $(.002)$ & $(.002)$ \\
\hline \multirow[t]{2}{*}{ Parents } & .225 & .224 & .218 & .222 & .221 & .224 \\
\hline & $(.001)$ & $(.001)$ & $(.001)$ & $(.001)$ & $(.001)$ & $(.001)$ \\
\hline \multirow[t]{3}{*}{ Dynasty excl parents } & .103 & .122 & .172 & .181 & .189 & .186 \\
\hline & $(.001)$ & $(.001)$ & $(.002)$ & $(.002)$ & $(.002)$ & $(.002)$ \\
\hline & \multicolumn{6}{|c|}{ Panel B: Income } \\
\hline \multirow[t]{2}{*}{ Dynasty } & .930 & 1.051 & 1.265 & 1.383 & 1.474 & 1.524 \\
\hline & $(.005)$ & $(.005)$ & $(.006)$ & $(.007)$ & $(.008)$ & $(.008)$ \\
\hline \multirow[t]{2}{*}{ Parents } & .582 & .577 & .568 & .571 & .568 & .570 \\
\hline & $(.004)$ & $(.004)$ & $(.004)$ & $(.004)$ & $(.004)$ & $(.004)$ \\
\hline \multirow[t]{3}{*}{ Dynast excl parents } & .306 & .398 & .568 & .645 & .723 & .760 \\
\hline & $(.004)$ & $(.005)$ & $(.007)$ & $(.008)$ & $(.008)$ & $(.009)$ \\
\hline & \multicolumn{6}{|c|}{ Panel C: Social status } \\
\hline \multirow[t]{2}{*}{ Dynasty } & .050 & .057 & .067 & .072 & .075 & .076 \\
\hline & $(.000)$ & $(.000)$ & $(.000)$ & $(.000)$ & $(.000)$ & $(.000)$ \\
\hline \multirow[t]{2}{*}{ Parents } & .032 & .031 & .031 & .031 & .031 & .031 \\
\hline & $(.000)$ & $(.000)$ & $(.000)$ & $(.000)$ & $(.000)$ & $(.000)$ \\
\hline \multirow[t]{3}{*}{ Dynasty excl parents } & .016 & .023 & .031 & .034 & .037 & .038 \\
\hline & $(.000)$ & $(.000)$ & $(.000)$ & $(.000)$ & $(.000)$ & $(.000)$ \\
\hline & \multicolumn{6}{|c|}{ Panel D: Schooling, income, and social status } \\
\hline \multirow[t]{2}{*}{ Dynasty } & .426 & .441 & .513 & .538 & .547 & .541 \\
\hline & $(.001)$ & $(.001)$ & $(.002)$ & $(.002)$ & $(.002)$ & $(.002)$ \\
\hline \multirow[t]{2}{*}{ Parents } & .300 & .300 & .294 & .298 & .299 & .302 \\
\hline & $(.001)$ & $(.001)$ & $(.001)$ & $(.001)$ & $(.001)$ & $(.001)$ \\
\hline \multirow[t]{2}{*}{ Dynasty excl parents } & .107 & .121 & .167 & .174 & .179 & .174 \\
\hline & $(.001)$ & $(.002)$ & $(.002)$ & $(.002)$ & $(.002)$ & $(.002)$ \\
\hline Parents' siblings & Yes & Yes & Yes & Yes & Yes & Yes \\
\hline Spouses of aunts/uncles & No & Yes & Yes & Yes & Yes & Yes \\
\hline Parents' cousins & No & No & Yes & Yes & Yes & Yes \\
\hline Spouses' of parents' cousins & No & No & No & Yes & Yes & Yes \\
\hline $\begin{array}{l}\text { Siblings of spouses of } \\
\text { aunts/uncles }\end{array}$ & No & No & No & No & Yes & Yes \\
\hline $\begin{array}{l}\text { Spouses of siblings of spouses of } \\
\text { aunts/uncles }\end{array}$ & No & No & No & No & No & Yes \\
\hline$N$ & 647,250 & 647,250 & 647,250 & 647,250 & 647,250 & 647,250 \\
\hline
\end{tabular}

Note: The dependent variable is the child's years of schooling for those aged at least 30, and predicted years of schooling based on 9th grade GPA and high school track for those aged below 30. Parental variables are averages across parents, while dynasty variables are averages over the indicated types of relatives. Dynasty includes parents, while Dynasty excl parents excludes them. All regressions include linear and quadratic controls for average years of birth for each included type of relative. Robust standard errors in parentheses. 
Table A2a. Results from OLS regressions of the child's predicted years of schooling on successively additional components of the dynasty. Income

\begin{tabular}{|c|c|c|c|c|c|c|}
\hline & (1) & (2) & (3) & (4) & (5) & (6) \\
\hline \multirow[t]{2}{*}{ Parents } & .643 & .582 & .569 & .561 & .559 & .555 \\
\hline & $(.003)$ & $(.004)$ & $(.004)$ & $(.004)$ & $(.004)$ & $(.004)$ \\
\hline \multirow[t]{2}{*}{ Parents' siblings } & & .306 & .277 & .267 & .265 & .256 \\
\hline & & $(.004)$ & $(.004)$ & $(.004)$ & $(.004)$ & $(.004)$ \\
\hline \multirow[t]{2}{*}{ Spouses of aunts/uncles } & & & .143 & .138 & .136 & .121 \\
\hline & & & $(.004)$ & $(.004)$ & $(.004)$ & $(.004)$ \\
\hline \multirow[t]{2}{*}{ Parents' cousins } & & & & .164 & .144 & .141 \\
\hline & & & & $(.005)$ & $(.005)$ & $(.005)$ \\
\hline \multirow[t]{2}{*}{ Spouses of parents' cousins } & & & & & .091 & .088 \\
\hline & & & & & $(.005)$ & $(.005)$ \\
\hline Siblings of spouses of & & & & & & .119 \\
\hline aunts/uncles & & & & & & $(.005)$ \\
\hline \multirow[t]{2}{*}{ Sum of estimates } & .643 & .887 & .989 & 1.131 & 1.195 & 1.280 \\
\hline & $(.003)$ & $(.005)$ & $(.006)$ & $(.007)$ & $(.008)$ & $(.008)$ \\
\hline$R^{2}$ & .100 & .107 & .109 & .111 & .111 & .113 \\
\hline$N$ & 647,250 & 647,250 & 647,250 & 647,250 & 647,250 & 647,250 \\
\hline
\end{tabular}

Note: The dependent variable is the child's years of schooling for those aged at least 30, and predicted years of schooling based on 9th grade GPA and high school track for those aged below 30. The explanatory variables are average lifetime incomes for each type of relatives. The lower panel shows sums of coefficients. All regressions include linear and quadratic controls for average years of birth for each included type of relative. Robust standard errors in parentheses.

Table A2b. Results from OLS regressions of the child's predicted years of schooling on successively additional components of the dynasties. Occupational status

\begin{tabular}{lrrrrrr}
\hline & $(1)$ & $(2)$ & $(3)$ & $(4)$ & $(5)$ & $(6)$ \\
\hline Parents & .036 & .032 & .031 & .030 & .030 & .030 \\
& $(.000)$ & $(.000)$ & $(.000)$ & $(.000)$ & $(.000)$ & $(.000)$ \\
Parents' siblings & & .016 & .015 & .014 & .014 & .013 \\
& & $.000)$ & $(.000)$ & $(.000)$ & $(.000)$ & $(.000)$ \\
Spouses of aunts/uncles & & & .010 & .010 & .010 & .009 \\
& & & $(.000)$ & $(.000)$ & $(.000)$ & $(.000)$ \\
Parents' cousins & & & & .007 & .006 & .006 \\
& & & & $(.000)$ & $(.000)$ & $(.000)$ \\
Spouses of parents' cousins & & & & & .004 & .004 \\
& & & & & $(.000)$ & $(.000)$ \\
Siblings of spouses of & & & & & .005 \\
aunts/uncles & & & & & & $(.000)$ \\
\hline Sum of estimates & .036 & .049 & .056 & .061 & .064 & .067 \\
& $(.000)$ & $.000)$ & $(.000)$ & $(.000)$ & $(.000)$ & $(.000)$ \\
\hline$R^{2}$ & .108 & .117 & .121 & .122 & .123 & .124 \\
$N$ & 647,250 & 647,250 & 647,250 & 647,250 & 647,250 & 647,250 \\
\hline
\end{tabular}

Note: The dependent variable is the child's years of schooling for those aged at least 30, and predicted years of schooling based on 9th grade GPA and high school track for those aged below 30. Explanatory variables are average social stratification measures for each type of relatives. The lower panel shows sums of coefficients. All regressions include linear and quadratic controls for average years of birth for each included type of relative. Robust standard errors in parentheses. 
Table A3. Results from OLS regressions of the child's predicted years of schooling on different outcomes for all relatives

\begin{tabular}{|c|c|c|c|c|c|}
\hline & $\begin{array}{r}(1) \\
\text { Schooling }\end{array}$ & $\begin{array}{r}(2) \\
\text { Income }\end{array}$ & $\begin{array}{r}\text { (3) } \\
\text { Occupation }\end{array}$ & $\begin{array}{r}(4) \\
\text { Schooling and } \\
\text { income }\end{array}$ & $\begin{array}{r}(5) \\
\text { Schooling, } \\
\text { income, and } \\
\text { occupation }\end{array}$ \\
\hline \multirow[t]{2}{*}{ Parents } & .206 & .513 & .027 & .261 & .282 \\
\hline & $(.001)$ & $(.004)$ & $(.000)$ & $(.001)$ & $(.001)$ \\
\hline \multirow[t]{2}{*}{ Grandparents } & .014 & .200 & .010 & .015 & .012 \\
\hline & $(.001)$ & $(.005)$ & $(.000)$ & $(.001)$ & $(.002)$ \\
\hline \multirow[t]{2}{*}{ Great grandparents } & -.011 & .004 & -.000 & -.014 & -.022 \\
\hline & $(.002)$ & $(.003)$ & $(.000)$ & $(.003)$ & $(.005)$ \\
\hline \multirow[t]{2}{*}{ Parents' siblings } & .077 & .214 & .011 & .082 & .082 \\
\hline & $(.001)$ & $(.004)$ & $(.000)$ & $(.002)$ & $(.002)$ \\
\hline \multirow[t]{2}{*}{ Spouses of aunts/uncles } & .025 & .105 & .007 & .023 & .025 \\
\hline & $(.001)$ & $(.004)$ & $(.000)$ & $(.001)$ & $(.002)$ \\
\hline \multirow[t]{2}{*}{ Parents' cousins } & .042 & .092 & .003 & .039 & .039 \\
\hline & $(.002)$ & $(.005)$ & $(.000)$ & $(.002)$ & $(.002)$ \\
\hline Spouses of parents' & .006 & .065 & .002 & .005 & .005 \\
\hline cousins & $(.002)$ & $(.005)$ & $(.000)$ & $(.002)$ & $(.002)$ \\
\hline \multirow{2}{*}{$\begin{array}{l}\text { Siblings of spouses of } \\
\text { aunts/uncles }\end{array}$} & .019 & .101 & .004 & .017 & .014 \\
\hline & $(.001)$ & $(.005)$ & $(.000)$ & $(.001)$ & $(.002)$ \\
\hline \multirow[t]{2}{*}{ Parents' aunts/uncles } & .003 & .085 & .004 & .005 & .005 \\
\hline & $(.001)$ & $(.005)$ & $(.000)$ & $(.001)$ & $(.001)$ \\
\hline \multirow[t]{2}{*}{ Sum of coefficients } & .381 & 1.377 & .069 & .433 & .441 \\
\hline & $(.003)$ & $(.009)$ & $(.000)$ & $(.003)$ & $(.005)$ \\
\hline$R^{2}$ & .161 & .122 & .132 & .181 & .185 \\
\hline$N$ & 647,250 & 647,250 & 647,250 & 647,250 & 647,250 \\
\hline \multicolumn{6}{|c|}{$\begin{array}{l}\text { Note: The dependent variable is the child's years of schooling for those aged at least 30, and predicted years of } \\
\text { schooling based on 9th grade GPA and high school track for those aged below 30. Explanatory variables are average } \\
\text { outcomes for each type of relatives. Columns } 4 \text { and } 5 \text { show Lubotsky \& Wittenberg-type weighted sums, normalized } \\
\text { to be comparable to the schooling coefficients. The lower panel shows sums of coefficients. All regressions include } \\
\text { linear and quadratic controls for average years of birth for each included type of relative. Robust standard errors in } \\
\text { parentheses. }\end{array}$} \\
\hline
\end{tabular}


Table A4a. Results from OLS regressions of the child's predicted years of schooling on ancestors' income

\begin{tabular}{lrrrrrr}
\hline & $(1)$ & $(2)$ & $(3)$ & $(4)$ & $(5)$ & $(6)$ \\
\hline Parents & .643 & & .587 & & .581 & .573 \\
Grandparents & $(.003)$ & & $(.003)$ & & $(.003)$ & $(.003)$ \\
& & .461 & .288 & & .285 & .265 \\
Great grandparents & & $(.004)$ & $(.005)$ & & $(.005)$ & $(.005)$ \\
& & & & .052 & .016 & .009 \\
Parents' aunts/uncles & & & & $(.003)$ & $(.003)$ & $(.003)$ \\
& & & & & .132 \\
Sum of coefficients & .643 & .461 & .875 & .052 & .881 & .979 \\
& $(.003)$ & $(.004)$ & $(.005)$ & $(.003)$ & $(.006)$ & $(.006)$ \\
$R^{2}$ & .100 & .068 & .109 & .049 & .111 & .113 \\
$N$ & 647,250 & 647,250 & 647,250 & 647,250 & 647,250 & 647,250 \\
\hline
\end{tabular}

Note: The dependent variable is the child's years of schooling for those aged at least 30, and predicted years of schooling based on 9th grade GPA and high school track for those aged below 30. Explanatory variables are average average lifetime incomes for each type of relatives. The lower panel shows sums of coefficients. All regressions include linear and quadratic controls for average years of birth for each included type of relative. Robust standard errors in parentheses.

Table A4b. Results from OLS regressions of the child's predicted years of schooling on ancestors' occupational status

\begin{tabular}{|c|c|c|c|c|c|c|}
\hline & $(1)$ & (2) & (3) & (4) & (5) & (6) \\
\hline \multirow[t]{2}{*}{ Parents } & .036 & & .031 & & .031 & .030 \\
\hline & $(.000)$ & & $(.000)$ & & $(.000)$ & $(.000)$ \\
\hline \multirow[t]{2}{*}{ Grandparents } & & .030 & .017 & & .017 & .015 \\
\hline & & $(.000)$ & $(.000)$ & & $(.000)$ & $(.000)$ \\
\hline \multirow[t]{2}{*}{ Great grandparents } & & & & .008 & .001 & .000 \\
\hline & & & & $(.000)$ & $(.000)$ & $(.000)$ \\
\hline \multirow[t]{2}{*}{ Parents' aunts/uncles } & & & & & & .007 \\
\hline & & & & & & $(.000)$ \\
\hline \multirow[t]{2}{*}{ Sum of coefficients } & .036 & .030 & .049 & .008 & .049 & .053 \\
\hline & $(.000)$ & $(.000)$ & $(.000)$ & $(.000)$ & $(.000)$ & $(.000)$ \\
\hline$R^{2}$ & .108 & .079 & .120 & .050 & .121 & .123 \\
\hline$N$ & 647,250 & 647,250 & 647,250 & 647,250 & 647,250 & 647,250 \\
\hline
\end{tabular}

Note: The dependent variable is the child's years of schooling for those aged at least 30, and predicted years of schooling based on 9th grade GPA and high school track for those aged below 30. Explanatory variables are average social stratification measures for each type of relatives. The lower panel shows sums of coefficients. All regressions include linear and quadratic controls for average years of birth for each included type of relative. Robust standard errors in parentheses. 
Table A5a. Results from OLS regressions of the child's predicted years of schooling on outcomes for ancestors. First three generations

\begin{tabular}{|c|c|c|c|}
\hline & (1) & $(2)$ & (3) \\
\hline & \multicolumn{2}{|c|}{ Panel A: Schooling } & \\
\hline \multirow[t]{2}{*}{ Parents } & .307 & & .301 \\
\hline & $(.001)$ & & $(.001)$ \\
\hline \multirow[t]{2}{*}{ Grandparents } & & .267 & .052 \\
\hline & & $(.003)$ & $(.003)$ \\
\hline \multirow[t]{2}{*}{ Sum of estimates } & .307 & .267 & .353 \\
\hline & $(.001)$ & $(.003)$ & $(.003)$ \\
\hline \multirow[t]{2}{*}{$R^{2}$} & .121 & .029 & .124 \\
\hline & \multicolumn{3}{|c|}{ Panel B: Schooling and income } \\
\hline \multirow[t]{2}{*}{ Parents } & .354 & & .349 \\
\hline & $(.001)$ & & $(.001)$ \\
\hline \multirow[t]{2}{*}{ Grandparents } & & .273 & .046 \\
\hline & & $(.003)$ & $(.003)$ \\
\hline \multirow[t]{2}{*}{ Sum of estimates } & .354 & .273 & .394 \\
\hline & $(.001)$ & $(.003)$ & $(.003)$ \\
\hline \multirow[t]{2}{*}{$R^{2}$} & .127 & .029 & .130 \\
\hline & anel C: Sch & and social & \\
\hline \multirow[t]{2}{*}{ Parents } & .395 & & .389 \\
\hline & $(.001)$ & & $(.002)$ \\
\hline \multirow[t]{2}{*}{ Grandparents } & & .294 & .031 \\
\hline & & $(.004)$ & $(.003)$ \\
\hline \multirow[t]{2}{*}{ Sum of estimates } & .395 & .294 & .420 \\
\hline & $(.001)$ & $(.004)$ & $(.003)$ \\
\hline$R^{2}$ & .135 & .031 & .137 \\
\hline$N$ & 677,987 & 677,987 & 677,987 \\
\hline
\end{tabular}

Note: Regressions of third generation (the parental generation in out main specifications) years of schooling on average years of schooling, average lifetime incomes, and average social stratification measures for the second and first generations. Panels B and C show Lubotsky \& Wittenberg-type weighted sums, normalized to be comparable to the schooling coefficients. All regressions include linear and quadratic controls for average years of birth for each included type of relative. Robust standard errors in parentheses. 
Table A5b. Results from OLS regressions of the child's predicted years of schooling on outcomes for ancestors. First two generations

\begin{tabular}{lrrr}
\hline & $(1)$ & $(2)$ & $(3)$ \\
\hline Schooling & .452 & .426 & .339 \\
& $(.004)$ & $(.004)$ & $(.004)$ \\
Income & & .249 & .199 \\
& & $(.007)$ & $(.007)$ \\
Occupation & & & .031 \\
& & & $(.001)$ \\
\hline Parents & .452 & .481 & .540 \\
$R^{2}$ & $(.004)$ & $(.004)$ & $(.004)$ \\
$N$ & .065 & .069 & .082 \\
\hline
\end{tabular}

Note: Regressions of second generation (the grandparental generation in out main specifications) years of schooling on average years of schooling, average lifetime incomes, and average social stratification measures for the first generations. Panels B and C show Lubotsky \& Wittenberg-type weighted sums, normalized to be comparable to the schooling coefficients. All regressions include linear and quadratic controls for average years of birth for each included type of relative. Robust standard errors in parentheses. 
Table A6a. Results from OLS regressions of the child's GPA on three different measures of parental and dynastic human capital: Years of Schooling, income and occupational status index

\begin{tabular}{|c|c|c|c|c|}
\hline & (1) & (2) & (3) & (4) \\
\hline & \multicolumn{4}{|c|}{ Panel A: Years of schooling } \\
\hline \multirow[t]{2}{*}{ Parents' schooling } & 5.918 & & & 4.895 \\
\hline & (.019) & & & $(.021)$ \\
\hline \multirow[t]{2}{*}{ Dynasty schooling } & & 10.522 & & \\
\hline & & $(.036)$ & & \\
\hline \multirow[t]{2}{*}{ Dynasty schooling, excl parents } & & & 8.583 & 4.563 \\
\hline & & & $(.038)$ & $(.041)$ \\
\hline \multirow[t]{2}{*}{$R^{2}$} & .150 & .138 & .100 & .167 \\
\hline & \multicolumn{4}{|c|}{ Panel B: Income } \\
\hline \multirow[t]{2}{*}{ Parents' income } & 14.612 & & & 12.880 \\
\hline & $(.071)$ & & & $(.073)$ \\
\hline \multirow[t]{2}{*}{ Dynasty income } & & 33.660 & & \\
\hline & & $(.160)$ & & \\
\hline \multirow[t]{2}{*}{ Dynasty income, excl parents } & & & 24.209 & 16.670 \\
\hline & & & $(.166)$ & $(.166)$ \\
\hline \multirow[t]{2}{*}{$R^{2}$} & .095 & .093 & .062 & .111 \\
\hline & \multicolumn{4}{|c|}{ Panel C: Occupational status } \\
\hline \multirow[t]{2}{*}{ Parents' occupation } & .797 & & & .677 \\
\hline & $(.003)$ & & & $(.004)$ \\
\hline \multirow[t]{2}{*}{ Dynasty occupation } & & 1.681 & & \\
\hline & & $(.007)$ & & \\
\hline \multirow[t]{2}{*}{ Dynasty occupation, excl parents } & & & 1.283 & .842 \\
\hline & & & $(.008)$ & $(.008)$ \\
\hline$R^{2}$ & .102 & .101 & .071 & .119 \\
\hline$N$ & 647,250 & 647,250 & 647,250 & 647,250 \\
\hline
\end{tabular}

Note: The dependent variable is the child's 9th grade GPA. The parental variables are averages across parents, while dynasty variables are averages over parents, uncles and aunts, spouses of aunts/uncles, and parents' cousins. All regressions include linear and quadratic controls for average years of birth for each included type of relative. Robust standard errors in parentheses. 
Table A6b. Results from OLS regressions of the child's GPA on three different measures of parental and dynastic human capital: Years of Schooling and income

\begin{tabular}{|c|c|c|c|c|}
\hline & (1) & (2) & (3) & (4) \\
\hline \multirow[t]{2}{*}{ Parents' schooling } & 5.095 & & & 4.246 \\
\hline & $(.020)$ & & & $(.022)$ \\
\hline \multirow[t]{2}{*}{ Parents' income } & 9.914 & & & 8.890 \\
\hline & $(.069)$ & & & $(.070)$ \\
\hline \multirow[t]{2}{*}{ Dynasty schooling } & & 8.658 & & \\
\hline & & $(.041)$ & & \\
\hline \multirow[t]{2}{*}{ Dynasty income } & & 17.472 & & \\
\hline & & $(.174)$ & & \\
\hline \multirow[t]{2}{*}{ Dynasty schooling, excl parents } & & & 7.467 & 3.512 \\
\hline & & & $(.042)$ & $(.044)$ \\
\hline \multirow[t]{2}{*}{ Dynasty income, excl parents } & & & 1.832 & 5.594 \\
\hline & & & $(.179)$ & $(.171)$ \\
\hline \multirow[t]{2}{*}{ Parents } & 7.234 & & & 6.163 \\
\hline & $(.021)$ & & & $(.023)$ \\
\hline \multirow[t]{2}{*}{ Dynasty } & & 11.814 & & \\
\hline & & $(.038)$ & & \\
\hline \multirow[t]{2}{*}{ Dynastic excl par } & & & 9.227 & 4.421 \\
\hline & & & $(.039)$ & $(.042)$ \\
\hline$R^{2}$ & .179 & .151 & .105 & .193 \\
\hline$N$ & 647,250 & 647,250 & 647,250 & 647,250 \\
\hline
\end{tabular}

Note: The dependent variable is the child's 9th grade GPA. The parental variables are averages across parents, while dynasty variables are averages over parents, uncles and aunts, spouses of aunts/uncles, and parents' cousins. The lower panel shows Lubotsky \& Wittenberg-type weighted sums of the coefficients in the upper panel, normalized to be comparable to the schooling coefficients. All regressions include linear and quadratic controls for average years of birth for each included type of relative. Robust standard errors in parentheses. 
Table A6c. Results from OLS regressions of the child's GPA on three different measures of parental and dynastic human capital: Years of Schooling, income and occupational status index

\begin{tabular}{|c|c|c|c|c|}
\hline & (1) & (2) & (3) & (4) \\
\hline \multirow[t]{2}{*}{ Parents' schooling } & 4.375 & & & 3.708 \\
\hline & $(.023)$ & & & $(.024)$ \\
\hline \multirow[t]{2}{*}{ Parents' income } & 9.057 & & & 8.240 \\
\hline & $(.070)$ & & & $(.070)$ \\
\hline \multirow[t]{2}{*}{ Parents' occupation } & .269 & & & .219 \\
\hline & $(.004)$ & & & $(.004)$ \\
\hline \multirow[t]{2}{*}{ Dynasty schooling } & & 7.534 & & \\
\hline & & $(.052)$ & & \\
\hline \multirow[t]{2}{*}{ Dynasty income } & & 16.397 & & \\
\hline & & $(.176)$ & & \\
\hline \multirow[t]{2}{*}{ Dynasty occupation } & & .359 & & \\
\hline & & $(.010)$ & & \\
\hline \multirow[t]{2}{*}{ Dynasty schooling, excl parents } & & & 6.630 & 3.049 \\
\hline & & & $(.052)$ & $(.051)$ \\
\hline \multirow[t]{2}{*}{ Dynasty income, excl parents } & & & 10.060 & 5.211 \\
\hline & & & $(.180)$ & $(.173)$ \\
\hline \multirow[t]{2}{*}{ Dynasty occupation, excl parents } & & & .278 & .071 \\
\hline & & & $(.010)$ & $(.009)$ \\
\hline \multirow[t]{2}{*}{ Parents } & 7.544 & & & 6.476 \\
\hline & $(.021)$ & & & $(.024)$ \\
\hline \multirow[t]{2}{*}{ Dynasty } & & 12.025 & & \\
\hline & & $(.038)$ & & \\
\hline \multirow[t]{2}{*}{ Dynastic excl par } & & & 9.404 & 4.187 \\
\hline & & & $(.040)$ & $(.043)$ \\
\hline$R^{2}$ & .184 & .153 & .106 & .197 \\
\hline$N$ & 647,250 & 647,250 & 647,250 & 647,250 \\
\hline
\end{tabular}

Note: The dependent variable is the child's 9th grade GPA. The parental variables are averages across parents, while dynasty variables are averages over parents, uncles and aunts, spouses of aunts/uncles, and parents' cousins. The lower panel shows Lubotsky \& Wittenberg-type weighted sums of the coefficients in the upper panel, normalized to be comparable to the schooling coefficients. All regressions include linear and quadratic controls for average years of birth for each included type of relative. Robust standard errors in parentheses. 
Table A6d. Results from OLS regressions of the child's GPA on extended family income

\begin{tabular}{lrrrrrr}
\hline & $(1)$ & $(2)$ & $(3)$ & $(4)$ & $(5)$ & $(6)$ \\
\hline Parents & 14.612 & 13.164 & 12.897 & 12.699 & 12.646 & 12.552 \\
& $(.071)$ & $(.073)$ & $(.073)$ & $(.073)$ & $(.073)$ & $(.073)$ \\
Parents' siblings & & 7.155 & 6.519 & 6.282 & 6.234 & 6.041 \\
& & $(.087)$ & $(.089)$ & $(.089)$ & $(.089)$ & $(.089)$ \\
Spouses of aunts/uncles & & & 3.143 & 3.038 & 2.995 & 2.631 \\
& & & $(.088)$ & $(.088)$ & $(.088)$ & $(.089)$ \\
Parents' cousins & & & & 3.850 & 3.364 & 3.299 \\
& & & & $(.096)$ & $(.099)$ & $(.099)$ \\
Spouses of parents' cousins & & & & & 2.109 & 2.047 \\
& & & & & $(.101)$ & $(.101)$ \\
Siblings of spouses of & & & & & & 2.715 \\
aunts/uncles & & & & & & \\
\hline Sum of estimates & 14.612 & 20.319 & 22.559 & 25.869 & 27.348 & 29.284 \\
& $(.071)$ & $(.097)$ & $(.114)$ & $(.139)$ & $(.155)$ & $(.168)$ \\
\hline$R^{2}$ & .095 & .106 & .108 & .110 & .111 & .113 \\
$N$ & 647,250 & 647,250 & 647,250 & 647,250 & 647,250 & 647,250 \\
\hline
\end{tabular}

Note: The dependent variable is the child's 9th grade GPA. The explanatory variables are average lifetime incomes for each type of relatives. The lower panel shows sums of coefficients. All regressions include linear and quadratic controls for average years of birth for each included type of relative. Robust standard errors in parentheses.

Table A6e. Results from OLS regressions of the child's GPA on extended family occupation status index

\begin{tabular}{|c|c|c|c|c|c|c|}
\hline & (1) & (2) & (3) & (4) & (5) & (6) \\
\hline \multirow[t]{2}{*}{ Parents } & .797 & .709 & .676 & .667 & .662 & .656 \\
\hline & $(.003)$ & $(.004)$ & $(.004)$ & $(.004)$ & $(.004)$ & $(.004)$ \\
\hline \multirow[t]{2}{*}{ Parents' siblings } & & .368 & .331 & .321 & .316 & .303 \\
\hline & & $(.004)$ & $(.004)$ & $(.004)$ & $(.004)$ & $(.004)$ \\
\hline \multirow[t]{2}{*}{ Spouses of aunts/uncles } & & & .227 & .222 & .218 & .199 \\
\hline & & & $(.004)$ & $(.004)$ & $(.004)$ & $(.004)$ \\
\hline \multirow[t]{2}{*}{ Parents' cousins } & & & & .149 & .137 & .134 \\
\hline & & & & $(.005)$ & $(.005)$ & $(.005)$ \\
\hline \multirow[t]{2}{*}{ Spouses of parents' cousins } & & & & & .104 & .102 \\
\hline & & & & & $(.004)$ & $(.004)$ \\
\hline Siblings of spouses of & & & & & & .109 \\
\hline aunts/uncles & & & & & & $(.005)$ \\
\hline \multirow[t]{2}{*}{ Sum of estimates } & .797 & 1.077 & 1.234 & 1.358 & 1.438 & 1.503 \\
\hline & $(.003)$ & $(.005)$ & $(.005)$ & $(.006)$ & $(.007)$ & $(.008)$ \\
\hline$R^{2}$ & .102 & .113 & .118 & .120 & .120 & .121 \\
\hline$N$ & 647,250 & 647,250 & 647,250 & 647,250 & 647,250 & 647,250 \\
\hline
\end{tabular}

Note: The dependent variable is the child's 9th grade GPA. The explanatory variables are average social stratification measures for each type of relatives. The lower panel shows sums of coefficients. All regressions include linear and quadratic controls for average years of birth for each included type of relative. Robust standard errors in parentheses. 
Table A6f. Results from OLS regressions of the child's GPA on successively additional components of the dynasties. Schooling, income and social stratification

\begin{tabular}{|c|c|c|c|c|c|c|}
\hline & $(1)$ & $(2)$ & (3) & $(4)$ & $(5)$ & (6) \\
\hline & \multicolumn{6}{|c|}{ Panel A: Schooling } \\
\hline \multirow[t]{2}{*}{ Parents } & 5.918 & 5.016 & 4.898 & 4.751 & 4.740 & 4.716 \\
\hline & $(.019)$ & $(.021)$ & $(.022)$ & $(.022)$ & $(.022)$ & $(.022)$ \\
\hline \multirow[t]{2}{*}{ Parents' siblings } & & 2.410 & 2.093 & 1.933 & 1.922 & 1.852 \\
\hline & & $(.025)$ & $(.028)$ & $(.028)$ & $(.028)$ & $(.028)$ \\
\hline \multirow[t]{2}{*}{ Spouses of aunts/uncles } & & & .897 & .831 & .824 & .664 \\
\hline & & & $(.025)$ & $(.025)$ & $(.025)$ & $(.026)$ \\
\hline \multirow[t]{2}{*}{ Parents' cousins } & & & & 1.428 & 1.223 & 1.208 \\
\hline & & & & $(.029)$ & $(.033)$ & $(.033)$ \\
\hline \multirow[t]{2}{*}{ Spouses of parents' cousins } & & & & & .394 & .385 \\
\hline & & & & & $(.031)$ & $(.031)$ \\
\hline \multirow{2}{*}{$\begin{array}{l}\text { Siblings of spouses of } \\
\text { aunts/uncles }\end{array}$} & & & & & & .523 \\
\hline & & & & & & $(.027)$ \\
\hline \multirow[t]{2}{*}{ Sum of estimates } & 5.918 & 7.426 & 7.888 & 8.943 & 9.102 & 9.348 \\
\hline & $(.019)$ & $(.024)$ & $(.027)$ & $(.034)$ & $(.036)$ & $(.038)$ \\
\hline \multirow[t]{2}{*}{$R^{2}$} & .150 & .163 & .166 & .169 & .169 & .170 \\
\hline & \multicolumn{6}{|c|}{ Panel B: Schooling and income } \\
\hline \multirow[t]{2}{*}{ Parents } & 7.234 & 6.242 & 6.130 & 5.979 & 5.969 & 5.946 \\
\hline & $(.021)$ & $(.023)$ & $(.023)$ & $(.024)$ & $(.024)$ & $(.024)$ \\
\hline \multirow[t]{2}{*}{ Parents' siblings } & & 2.517 & 2.230 & 2.071 & 2.061 & 2.002 \\
\hline & & $(.027)$ & $(.029)$ & $(.030)$ & $(.030)$ & $(.030)$ \\
\hline \multirow[t]{2}{*}{ Spouses of aunts/uncles } & & & .784 & .725 & .719 & .576 \\
\hline & & & $(.026)$ & $(.026)$ & $(.026)$ & $(.028)$ \\
\hline \multirow[t]{2}{*}{ Parents' cousins } & & & & 1.344 & 1.159 & 1.146 \\
\hline & & & & $(.029)$ & $(.034)$ & $(.034)$ \\
\hline \multirow[t]{2}{*}{ Spouses of parents' cousins } & & & & & .348 & .340 \\
\hline & & & & & $(.032)$ & $(.032)$ \\
\hline \multirow{2}{*}{$\begin{array}{l}\text { Siblings of spouses of } \\
\text { aunts/uncles }\end{array}$} & & & & & & .452 \\
\hline & & & & & & $(.028)$ \\
\hline \multirow[t]{2}{*}{ Sum of estimates } & 7.234 & 8.759 & 9.144 & 10.120 & 10.256 & 10.461 \\
\hline & .021 & .025 & .028 & .034 & .037 & .039 \\
\hline$R^{2}$ & .179 & .190 & .192 & .195 & .195 & .196 \\
\hline
\end{tabular}




\begin{tabular}{|c|c|c|c|c|c|c|}
\hline & $(1)$ & $(2)$ & (3) & $(4)$ & (5) & (6) \\
\hline & \multicolumn{6}{|c|}{ Panel C: Schooling, income, and social stratification } \\
\hline \multirow[t]{2}{*}{ Parents } & 7.544 & 6.535 & 6.425 & 6.276 & 6.265 & 6.248 \\
\hline & $(.021)$ & $(.024)$ & $(.024)$ & $(.024)$ & $(.024)$ & $(.024)$ \\
\hline \multirow[t]{2}{*}{ Parents' siblings } & & 2.453 & 2.153 & 2.002 & 1.992 & 1.942 \\
\hline & & $(.027)$ & $(.030)$ & $(.030)$ & $(.030)$ & $(.030)$ \\
\hline \multirow[t]{2}{*}{ Spouses of aunts/uncles } & & & .768 & .712 & .705 & .584 \\
\hline & & & $(.027)$ & $(.027)$ & $(.027)$ & $(.029)$ \\
\hline \multirow[t]{2}{*}{ Parents' cousins } & & & & 1.280 & 1.111 & 1.100 \\
\hline & & & & $(.029)$ & $(.034)$ & $(.034)$ \\
\hline \multirow[t]{2}{*}{ Spouses of parents' cousins } & & & & & .315 & .309 \\
\hline & & & & & $(.033)$ & $(.033)$ \\
\hline Siblings of spouses of & & & & & & .363 \\
\hline aunts/uncles & & & & & & $(.029)$ \\
\hline \multirow[t]{2}{*}{ Sum of estimates } & 7.544 & 8.987 & 9.346 & 10.270 & 10.389 & 10.547 \\
\hline & $(.021)$ & $(.026)$ & $(.028)$ & $(.035)$ & $(.037)$ & $(.040)$ \\
\hline$R^{2}$ & .184 & .195 & .197 & .199 & .200 & .200 \\
\hline$N$ & 647,250 & 647,250 & 647,250 & 647,250 & 647,250 & 647,250 \\
\hline
\end{tabular}

Note: The dependent variable is the child's 9th grade GPA. The explanatory variables are average years of schooling, average lifetime incomes, and average social stratification measures for each type of relatives. All regressions include linear and quadratic controls for average years of birth for each included type of relative. Robust standard errors in parentheses. 
Table A6g. Results from OLS regressions of the child's GPA on ancestor outcomes

\begin{tabular}{|c|c|c|c|c|c|c|}
\hline & $(1)$ & $(2)$ & (3) & $(4)$ & $(5)$ & (6) \\
\hline & \multicolumn{6}{|c|}{ Panel A: Schooling } \\
\hline \multirow[t]{2}{*}{ Parents } & 5.918 & & 5.326 & & 5.268 & 5.206 \\
\hline & $(.019)$ & & $(.021)$ & & $(.021)$ & $(.021)$ \\
\hline \multirow[t]{2}{*}{ Grandparents } & & 3.419 & 1.257 & & 1.213 & 1.046 \\
\hline & & $(.020)$ & $(.021)$ & & $(.022)$ & $(.023)$ \\
\hline \multirow[t]{2}{*}{ Great grandparents } & & & & 2.421 & .196 & -.064 \\
\hline & & & & $(.044)$ & $(.043)$ & $(.044)$ \\
\hline \multirow[t]{2}{*}{ Parents' aunts/uncles } & & & & & & .546 \\
\hline & & & & & & $(.020)$ \\
\hline \multirow[t]{2}{*}{ Sum of estimates } & 5.918 & 3.419 & 6.583 & 2.421 & 6.677 & 6.733 \\
\hline & $(.019)$ & $(.020)$ & $(.023)$ & $(.044)$ & $(.043)$ & $(.043)$ \\
\hline \multirow[t]{2}{*}{$R^{2}$} & .150 & .077 & .159 & .036 & .161 & .162 \\
\hline & \multicolumn{6}{|c|}{ Panel B: Schooling and income } \\
\hline \multirow[t]{2}{*}{ Parents } & 7.234 & & 6.629 & & 6.566 & 6.500 \\
\hline & $(.021)$ & & $(.023)$ & & $(.023)$ & $(.023)$ \\
\hline \multirow[t]{2}{*}{ Grandparents } & & 3.828 & 1.216 & & 1.183 & 1.013 \\
\hline & & $(.021)$ & $(.022)$ & & $(.023)$ & $(.024)$ \\
\hline \multirow[t]{2}{*}{ Great grandparents } & & & & 2.583 & .136 & -.131 \\
\hline & & & & $(.047)$ & $(.045)$ & $(.046)$ \\
\hline \multirow[t]{2}{*}{ Parents' aunts/uncles } & & & & & & .562 \\
\hline & & & & & & $(.021)$ \\
\hline \multirow[t]{2}{*}{ Sum of estimates } & 7.234 & 3.828 & 7.846 & 2.583 & 7.886 & 7.945 \\
\hline & $(.021)$ & $(.021)$ & $(.024)$ & $(.047)$ & $(.046)$ & $(.046)$ \\
\hline \multirow[t]{2}{*}{$R^{2}$} & .179 & .081 & .186 & .037 & .188 & .189 \\
\hline & \multicolumn{6}{|c|}{ Panel C: Schooling, income, and social stratification } \\
\hline \multirow[t]{2}{*}{ Parents } & 7.544 & & 6.927 & & 6.864 & 6.803 \\
\hline & $(.021)$ & & $(.024)$ & & $(.024)$ & $(.024)$ \\
\hline \multirow[t]{2}{*}{ Grandparents } & & 4.242 & 1.190 & & 1.155 & .982 \\
\hline & & $(.022)$ & $(.024)$ & & $(.025)$ & $(.026)$ \\
\hline \multirow[t]{2}{*}{ Great grandparents } & & & & 3.736 & .092 & -.256 \\
\hline & & & & $(.067)$ & $(.064)$ & $(.066)$ \\
\hline \multirow[t]{2}{*}{ Parents' aunts/uncles } & & & & & & .556 \\
\hline & & & & & & $(.022)$ \\
\hline \multirow[t]{2}{*}{ Sum of estimates } & 7.544 & 4.242 & 8.116 & 3.736 & 8.111 & 8.085 \\
\hline & $(.021)$ & $(.022)$ & $(.025)$ & $(.067)$ & $(.063)$ & $(.063)$ \\
\hline$R^{2}$ & .184 & .086 & .191 & .038 & .193 & .194 \\
\hline$N$ & 647,250 & 647,250 & 647,250 & 647,250 & 647,250 & 647,250 \\
\hline
\end{tabular}

Note: The dependent variable is the child's 9th grade GPA. Explanatory variables are average years of schooling, average lifetime incomes, and average social stratification measures for each type of relatives. Panels B and C show Lubotsky \& Wittenberg-type weighted sums, normalized to be comparable to the schooling coefficients. All regressions include linear and quadratic controls for average years of birth for each included type of relative. Robust standard errors in parentheses. 
Table A6h. Results from OLS regressions of the child's GPA on ancestors' income

\begin{tabular}{lrrrrrr}
\hline & $(1)$ & $(2)$ & $(3)$ & $(4)$ & $(5)$ & $(6)$ \\
\hline Parents & 14.612 & & 13.353 & & 13.176 & 13.007 \\
& $(.071)$ & & $(.072)$ & & $(.072)$ & $(.072)$ \\
Grandparents & & 10.102 & 6.215 & & 6.123 & 5.670 \\
& & $(.090)$ & $(.090)$ & & $(.090)$ & $(.091)$ \\
Great grandparents & & & & 1.090 & .280 & .128 \\
& & & & $(.063)$ & $(.060)$ & $(.060)$ \\
Parents' aunts/uncles & & & & & & 3.054 \\
& & & & & & \\
Sum of estimates & 14.612 & 10.102 & 19.568 & 1.090 & 19.579 & 21.859 \\
& $(.071)$ & $(.090)$ & $(.101)$ & $(.063)$ & $(.113)$ & $(.129)$ \\
$R^{2}$ & .095 & .055 & .109 & .032 & .112 & .114 \\
$N$ & 647,250 & 647,250 & 647,250 & 647,250 & 647,250 & 647,250 \\
\hline
\end{tabular}

Note: The dependent variable is the child's 9th grade GPA. Explanatory variables are average lifetime incomes for each type of relatives. The lower panel shows sums of coefficients. All regressions include linear and quadratic controls for average years of birth for each included type of relative. Robust standard errors in parentheses.

Table A6i. Results from OLS regressions of the child's GPA on ancestor occupational status

\begin{tabular}{lrrrrrr}
\hline & $(1)$ & $(2)$ & $(3)$ & $(4)$ & $(5)$ & $(6)$ \\
\hline Parents & .797 & & .678 & & .670 & .658 \\
Grandparents & $(.003)$ & & $(.004)$ & & $(.004)$ & $(.004)$ \\
& & .687 & .414 & & .396 & .358 \\
Great grandparents & & $(.004)$ & $(.005)$ & & $(.005)$ & $(.005)$ \\
& & & & .196 & .042 & .018 \\
Parents' aunts/uncles & & & & $(.005)$ & $(.004)$ & $(.004)$ \\
& & & & & .156 \\
Sum of estimates & .797 & .687 & 1.092 & .196 & 1.108 & 1.190 \\
& $(.003)$ & $(.004)$ & $(.005)$ & $(.005)$ & $(.006)$ & $(.006)$ \\
$R^{2}$ & .102 & .071 & .119 & .034 & .123 & .125 \\
$N$ & 647,250 & 647,250 & 647,250 & 647,250 & 647,250 & 647,250 \\
\hline
\end{tabular}

Note: The dependent variable is the child's 9th grade GPA. Explanatory variables are average social stratification measures for each type of relatives. The lower panel shows sums of coefficients. All regressions include linear and quadratic controls for average years of birth for each included type of relative. Robust standard errors in parentheses. 
Table A7. Results from OLS regressions of the child's predicted years of schooling on parental and dynastic years of schooling, with regional fixed effects

\begin{tabular}{|c|c|c|c|c|}
\hline & (1) & (2) & (3) & (4) \\
\hline & \multicolumn{4}{|c|}{ Panel A: Baseline } \\
\hline \multirow[t]{2}{*}{ Parents' schooling } & .264 & & & .222 \\
\hline & $(.001)$ & & & $(.001)$ \\
\hline \multirow[t]{2}{*}{ Dynasty schooling } & & .461 & & \\
\hline & & $(.002)$ & & \\
\hline \multirow[t]{2}{*}{ Dynasty schooling, excl parents } & & & .373 & .190 \\
\hline & & & $(.002)$ & $(.002)$ \\
\hline \multirow[t]{2}{*}{$R^{2}$} & .145 & .131 & .101 & .156 \\
\hline & \multicolumn{4}{|c|}{ Panel B: Municipality fixed effects } \\
\hline \multirow[t]{2}{*}{ Parents' schooling } & .263 & & & .223 \\
\hline & $(.002)$ & & & $(.002)$ \\
\hline \multirow[t]{2}{*}{ Dynasty schooling } & & .461 & & \\
\hline & & $(.004)$ & & \\
\hline \multirow[t]{2}{*}{ Dynasty schooling, excl parents } & & & .366 & .191 \\
\hline & & & $(.004)$ & $(.004)$ \\
\hline \multirow{2}{*}{$R^{2}$} & .148 & .134 & .104 & .160 \\
\hline & \multicolumn{4}{|c|}{ Panel C: Parish fixed effects } \\
\hline \multirow[t]{2}{*}{ Parents' schooling } & .259 & & & .221 \\
\hline & $(.002)$ & & & $(.002)$ \\
\hline \multirow[t]{2}{*}{ Dynasty schooling } & & .450 & & \\
\hline & & $(.003)$ & & \\
\hline \multirow[t]{2}{*}{ Dynasty schooling, excl parents } & & & .352 & .186 \\
\hline & & & $(.003)$ & $(.003)$ \\
\hline$R^{2}$ & .154 & .140 & .112 & .165 \\
\hline$N$ & 643,555 & 643,555 & 643,555 & 643,555 \\
\hline
\end{tabular}

Note: The dependent variable is the child's years of schooling for those aged at least 30, and predicted years of schooling based on 9th grade GPA and high school track for those aged below 30. Parental years of schooling are averages across parents, while dynasty years of schooling are averages over parents, parents' siblings, spouses of aunts/uncles, parents' cousins, spouses of parents' cousins, and siblings of spouses of aunts/uncles. All regressions include linear and quadratic controls for average years of birth for each included type of relative. Panel B includes 284 municipality fixed effects, and panel C includes 2,582 parish fixed effects. Robust standard errors in parentheses. Panels B and C show cluster-robust standard errors at the level of the fixed effects. 
Table A8a. Results from OLS regressions of the child's predicted years of schooling on parent and dynasty schooling, income and the social stratification index for occupational status. Children aged 30 and older

\begin{tabular}{|c|c|c|c|c|}
\hline & (1) & (2) & (3) & (4) \\
\hline & \multicolumn{3}{|c|}{ Panel A: Years of schooling } & \\
\hline \multirow[t]{2}{*}{ Parents' schooling } & .345 & & & .305 \\
\hline & $(.006)$ & & & $(.007)$ \\
\hline \multirow[t]{2}{*}{ Dynasty schooling } & & .610 & & \\
\hline & & $(.013)$ & & \\
\hline \multirow[t]{2}{*}{ Dynasty schooling, excl parents } & & & .443 & .253 \\
\hline & & & $(.013)$ & $(.013)$ \\
\hline \multirow[t]{2}{*}{$R^{2}$} & .087 & .073 & .048 & .098 \\
\hline & \multicolumn{3}{|c|}{ Panel B: Income } & \\
\hline \multirow[t]{2}{*}{ Parents' income } & .781 & & & .712 \\
\hline & $(.021)$ & & & $(.021)$ \\
\hline \multirow[t]{2}{*}{ Dynasty income } & & 1.764 & & \\
\hline & & $(.048)$ & & \\
\hline \multirow[t]{2}{*}{ Dynasty income, excl parents } & & & 1.164 & .835 \\
\hline & & & $(.049)$ & $(.049)$ \\
\hline \multirow[t]{2}{*}{$R^{2}$} & .053 & .049 & .032 & .061 \\
\hline & \multicolumn{3}{|c|}{ Panel C: Occupational status } & \\
\hline \multirow[t]{2}{*}{ Parents' occupation } & .045 & & & .041 \\
\hline & $(.001)$ & & & $(.001)$ \\
\hline \multirow[t]{2}{*}{ Dynasty occupation } & & .090 & & \\
\hline & & $(.002)$ & & \\
\hline \multirow[t]{2}{*}{ Dynasty occupation, excl parents } & & & .061 & .039 \\
\hline & & & $(.002)$ & $(.002)$ \\
\hline$R^{2}$ & .056 & .050 & .033 & .064 \\
\hline$N$ & 41,309 & 41,309 & 41,309 & 41,309 \\
\hline
\end{tabular}

Note: The dependent variable is the child's years of schooling. The sample is restricted to children aged 30 and older. Parental variables are averages across parents, while dynasty variables are averages over parents, uncles and aunts, spouses of aunts/uncles, and parents' cousins. All regressions include linear and quadratic controls for average years of birth for each included type of relative. Robust standard errors in parentheses. 
Table A8b. Results from OLS regressions of the child's predicted years of schooling on parent and dynasty schooling and income. Children aged 30 and older

\begin{tabular}{|c|c|c|c|c|}
\hline & (1) & $(2)$ & (3) & (4) \\
\hline \multirow[t]{2}{*}{ Parents' schooling } & .306 & & & .272 \\
\hline & $(.006)$ & & & $(.007)$ \\
\hline \multirow[t]{2}{*}{ Parents' income } & .574 & & & .527 \\
\hline & $(.020)$ & & & $(.020)$ \\
\hline \multirow[t]{2}{*}{ Dynasty schooling } & & .508 & & \\
\hline & & $(.014)$ & & \\
\hline \multirow[t]{2}{*}{ Dynasty income } & & .991 & & \\
\hline & & $(.052)$ & & \\
\hline \multirow[t]{2}{*}{ Dynasty schooling, excl parents } & & & .384 & .198 \\
\hline & & & $(.014)$ & $(.014)$ \\
\hline \multirow[t]{2}{*}{ Dynasty income, excl parents } & & & .565 & .331 \\
\hline & & & $(.053)$ & $(.051)$ \\
\hline \multirow[t]{2}{*}{ Parents } & .442 & & & .397 \\
\hline & $(.007)$ & & & $(.007)$ \\
\hline \multirow[t]{2}{*}{ Dynasty } & & .715 & & \\
\hline & & $(.014)$ & & \\
\hline \multirow[t]{2}{*}{ Dynastic excl par } & & & .492 & .262 \\
\hline & & & $(.013)$ & $(.014)$ \\
\hline$R^{2}$ & .105 & .082 & .050 & .116 \\
\hline$N$ & 41,309 & 41,309 & 41,309 & 41,309 \\
\hline
\end{tabular}

Note: The dependent variable is the child's years of schooling. The sample is restricted to children aged 30 and older. Parental variables are averages across parents, while dynasty variables are averages over parents, uncles and aunts, spouses of aunts/uncles, and parents' cousins. The lower panel shows Lubotsky \& Wittenberg-type weighted sums of the coefficients in the upper panel, normalized to be comparable to the schooling coefficients. All regressions include linear and quadratic controls for average years of birth for each included type of relative. Robust standard errors in parentheses. 
Table A8c. Results from OLS regressions of the child's predicted years of schooling on parent and dynasty schooling, income and the social stratification index for occupational status. Children aged 30 and older

\begin{tabular}{|c|c|c|c|c|}
\hline & (1) & (2) & (3) & (4) \\
\hline \multirow[t]{2}{*}{ Parents' schooling } & .267 & & & .242 \\
\hline & $(.007)$ & & & $(.007)$ \\
\hline \multirow[t]{2}{*}{ Parents' income } & .523 & & & .486 \\
\hline & $(.021)$ & & & $(.021)$ \\
\hline \multirow[t]{2}{*}{ Parents' occupation } & .016 & & & .014 \\
\hline & $(.001)$ & & & $(.001)$ \\
\hline \multirow[t]{2}{*}{ Dynasty schooling } & & .459 & & \\
\hline & & $(.017)$ & & \\
\hline \multirow[t]{2}{*}{ Dynasty income } & & .958 & & \\
\hline & & $(.052)$ & & \\
\hline \multirow[t]{2}{*}{ Dynasty occupation } & & .014 & & \\
\hline & & $(.003)$ & & \\
\hline \multirow[t]{2}{*}{ Dynasty schooling, excl parents } & & & .354 & .188 \\
\hline & & & $(.016)$ & $(.016)$ \\
\hline \multirow[t]{2}{*}{ Dynasty income, excl parents } & & & .551 & .333 \\
\hline & & & $(.053)$ & $(.052)$ \\
\hline \multirow[t]{2}{*}{ Dynasty occupation, excl parents } & & & .008 & -.004 \\
\hline & & & $(.003)$ & $(.003)$ \\
\hline \multirow[t]{2}{*}{ Parents } & .466 & & & .423 \\
\hline & $(.007)$ & & & $(.008)$ \\
\hline \multirow[t]{2}{*}{ Dynasty } & & .719 & & \\
\hline & & $(.014)$ & & \\
\hline \multirow[t]{2}{*}{ Dynastic excl par } & & & .491 & .236 \\
\hline & & & $(.014)$ & $(.014)$ \\
\hline$R^{2}$ & .109 & .081 & .049 & .118 \\
\hline$N$ & 41,309 & 41,309 & 41,309 & 41,309 \\
\hline
\end{tabular}

Note: The dependent variable is the child's years of schooling. The sample is restricted to children aged 30 and older. The parental variables are averages across parents, while dynasty variables are averages over parents, uncles and aunts, spouses of aunts/uncles, and parents' cousins. The lower panel shows Lubotsky \& Wittenberg-type weighted sums of the coefficients in the upper panel, normalized to be comparable to the schooling coefficients. All regressions include linear and quadratic controls for average years of birth for each included type of relative. Robust standard errors in parentheses. 
Table A8d. Results from OLS regressions of the child's predicted years of schooling on successively additional components of the dynasties. Income. Children aged 30 and older

\begin{tabular}{lrrrrrr}
\hline & $(1)$ & $(2)$ & $(3)$ & $(4)$ & $(5)$ & $(6)$ \\
\hline Parents & .781 & .708 & .698 & .692 & .691 & .687 \\
& $(.021)$ & $(.021)$ & $(.021)$ & $(.021)$ & $(.021)$ & $(.021)$ \\
Parents' siblings & & .433 & .396 & .385 & .383 & .375 \\
& & $.027)$ & $(.027)$ & $(.027)$ & $(.027)$ & $(.027)$ \\
Spouses of aunts/uncles & & & .173 & .168 & .167 & .152 \\
& & & $(.028)$ & $(.028)$ & $(.028)$ & $(.028)$ \\
Parents' cousins & & & & .151 & .134 & .133 \\
& & & & $(.024)$ & $(.025)$ & $(.025)$ \\
Spouses of parents' cousins & & & & & .074 & .071 \\
& & & & & $(.026)$ & $(.026)$ \\
Siblings of spouses of & & & & & .118 \\
aunts/uncles & & & & & $(.031)$ \\
\hline Sum of estimates & .781 & 1.140 & 1.268 & 1.397 & 1.450 & 1.537 \\
& $(.021)$ & $.030)$ & $(.036)$ & $(.041)$ & $(.045)$ & $(.051)$ \\
\hline$R^{2}$ & .053 & .060 & .061 & .062 & .062 & .063 \\
$N$ & 41,309 & 41,309 & 41,309 & 41,309 & 41,309 & 41,309 \\
\hline
\end{tabular}

Note: The dependent variable is the child's years of schooling for those aged at least 30 . The explanatory variables are average lifetime incomes for each type of relatives. The lower panel shows sums of coefficients. All regressions include linear and quadratic controls for average years of birth for each included type of relative. Robust standard errors in parentheses.

Table A8e. Results from OLS regressions of the child's predicted years of schooling on successively additional components of the dynasties. Occupation status index.

Children aged 30 and older

\begin{tabular}{lrrrrrr}
\hline & $(1)$ & $(2)$ & $(3)$ & $(4)$ & $(5)$ & $(6)$ \\
\hline Parents & .045 & .041 & .040 & .039 & .039 & .039 \\
& $(.001)$ & $(.001)$ & $(.001)$ & $(.001)$ & $(.001)$ & $(.001)$ \\
Parents' siblings & & .021 & .018 & .018 & .018 & .017 \\
& & $(.001)$ & $(.001)$ & $(.001)$ & $(.001)$ & $(.001)$ \\
Spouses of aunts/uncles & & & .012 & .012 & .012 & .011 \\
& & & $(.001)$ & $(.001)$ & $(.001)$ & $(.001)$ \\
Parents' cousins & & & & .007 & .007 & .007 \\
& & & & $(.001)$ & $(.001)$ & $(.001)$ \\
Spouses of parents' cousins & & & & & .002 & .002 \\
& & & & & $(.001)$ & $(.001)$ \\
Siblings of spouses of & & & & & .002 \\
aunts/uncles & & & & & & $(.002)$ \\
\hline Sum of estimates & .045 & .062 & .070 & .076 & .078 & .079 \\
& $(.001)$ & $.002)$ & $(.002)$ & $(.002)$ & $(.002)$ & $(.003)$ \\
\hline$R^{2}$ & .056 & .062 & .064 & .065 & .065 & .066 \\
$N$ & 41,309 & 41,309 & 41,309 & 41,309 & 41,309 & 41,309 \\
\hline
\end{tabular}

Note: The dependent variable is the child's years of schooling for those aged at least 30. The explanatory variables are average social stratification measures for each type of relatives. The lower panel shows sums of coefficients. All regressions include linear and quadratic controls for average years of birth for each included type of relative. Robust standard errors in parentheses. 
Table A8f. Results from OLS regressions of the child's predicted years of schooling on successively additional components of the dynasties. Schooling, income and social stratification. Children aged 30 and older

\begin{tabular}{|c|c|c|c|c|c|c|}
\hline & (1) & (2) & (3) & (4) & (5) & (6) \\
\hline & \multicolumn{6}{|c|}{ Panel A: Schooling } \\
\hline \multirow[t]{2}{*}{ Parents } & .345 & .303 & .297 & .292 & .292 & .291 \\
\hline & $(.006)$ & $(.007)$ & $(.007)$ & $(.007)$ & $(.007)$ & $(.007)$ \\
\hline \multirow[t]{2}{*}{ Parents' siblings } & & .150 & .139 & .132 & .132 & .130 \\
\hline & & $(.008)$ & $(.009)$ & $(.009)$ & $(.009)$ & $(.009)$ \\
\hline \multirow[t]{2}{*}{ Spouses of aunts/uncles } & & & .052 & .050 & .050 & .048 \\
\hline & & & $(.008)$ & $(.008)$ & $(.008)$ & $(.008)$ \\
\hline \multirow[t]{2}{*}{ Parents' cousins } & & & & .072 & .077 & .076 \\
\hline & & & & $(.008)$ & $(.009)$ & $(.009)$ \\
\hline \multirow[t]{2}{*}{ Spouses of parents' cousins } & & & & & -.009 & -.010 \\
\hline & & & & & $(.008)$ & $(.008)$ \\
\hline \multirow{2}{*}{$\begin{array}{l}\text { Siblings of spouses of } \\
\text { aunts/uncles }\end{array}$} & & & & & & .009 \\
\hline & & & & & & $(.008)$ \\
\hline \multirow[t]{2}{*}{ Sum of estimates } & .345 & .453 & .488 & .546 & .541 & .546 \\
\hline & $(.006)$ & $(.008)$ & $(.009)$ & $(.011)$ & $(.012)$ & $(.013)$ \\
\hline \multirow[t]{2}{*}{$R^{2}$} & .087 & .096 & .099 & .101 & .101 & .101 \\
\hline & \multicolumn{6}{|c|}{ Panel B: Schooling and income } \\
\hline \multirow[t]{2}{*}{ Parents } & .442 & .392 & .386 & .380 & .380 & .379 \\
\hline & $(.007)$ & $(.007)$ & $(.008)$ & $(.008)$ & $(.008)$ & $(.008)$ \\
\hline \multirow[t]{2}{*}{ Parents' siblings } & & .170 & .157 & .149 & .149 & .148 \\
\hline & & $(.009)$ & $(.010)$ & $(.010)$ & $(.010)$ & $(.010)$ \\
\hline \multirow[t]{2}{*}{ Spouses of aunts/uncles } & & & .049 & .047 & .048 & .047 \\
\hline & & & $(.008)$ & $(.008)$ & $(.008)$ & $(.009)$ \\
\hline \multirow[t]{2}{*}{ Parents' cousins } & & & & .069 & .074 & .074 \\
\hline & & & & $(.008)$ & $(.009)$ & $(.009)$ \\
\hline \multirow[t]{2}{*}{ Spouses of parents' cousins } & & & & & -.007 & -.008 \\
\hline & & & & & $(.009)$ & $(.009)$ \\
\hline \multirow{2}{*}{$\begin{array}{l}\text { Siblings of spouses of } \\
\text { aunts/uncles }\end{array}$} & & & & & & .004 \\
\hline & & & & & & $(.009)$ \\
\hline \multirow[t]{2}{*}{ Sum of estimates } & .442 & .562 & .592 & .646 & .644 & .645 \\
\hline & .007 & .009 & .010 & .012 & .013 & .014 \\
\hline$R^{2}$ & .105 & .115 & .117 & .119 & .119 & .119 \\
\hline
\end{tabular}




\begin{tabular}{|c|c|c|c|c|c|c|}
\hline & (1) & $(2)$ & $(3)$ & $(4)$ & $(5)$ & $(6)$ \\
\hline & \multicolumn{6}{|c|}{ Panel C: Schooling, income, and social stratification } \\
\hline \multirow[t]{2}{*}{ Parents } & .466 & .414 & .409 & .403 & .404 & .403 \\
\hline & $(.007)$ & $(.008)$ & $(.008)$ & $(.008)$ & $(.008)$ & $(.008)$ \\
\hline \multirow[t]{2}{*}{ Parents' siblings } & & .161 & .145 & .138 & .138 & .138 \\
\hline & & $(.009)$ & $(.010)$ & $(.010)$ & $(.010)$ & $(.010)$ \\
\hline \multirow[t]{2}{*}{ Spouses of aunts/uncles } & & & .047 & .045 & .046 & .047 \\
\hline & & & $(.009)$ & $(.009)$ & $(.009)$ & $(.009)$ \\
\hline \multirow[t]{2}{*}{ Parents' cousins } & & & & .067 & .072 & .072 \\
\hline & & & & $(.008)$ & $(.009)$ & $(.009)$ \\
\hline \multirow[t]{2}{*}{ Spouses of parents' cousins } & & & & & -.008 & -.008 \\
\hline & & & & & $(.009)$ & $(.009)$ \\
\hline \multirow{2}{*}{$\begin{array}{l}\text { Siblings of spouses of } \\
\text { aunts/uncles }\end{array}$} & & & & & & -.005 \\
\hline & & & & & & $(.010)$ \\
\hline \multirow[t]{2}{*}{ Sum of estimates } & .466 & .575 & .601 & .654 & .651 & .646 \\
\hline & $(.007)$ & $(.009)$ & $(.010)$ & $(.012)$ & $(.013)$ & $(.014)$ \\
\hline$R^{2}$ & .109 & .118 & .120 & .122 & .122 & .122 \\
\hline$N$ & 41,309 & 41,309 & 41,309 & 41,309 & 41,309 & 41,309 \\
\hline
\end{tabular}

Note: The dependent variable is the child's years of schooling for those aged at least 30 . The explanatory variables are average years of schooling, average lifetime incomes, and average social stratification measures for each type of relatives. All regressions include linear and quadratic controls for average years of birth for each included type of relative. Robust standard errors in parentheses. 
Table A8g. Results from OLS regressions of the child's predicted years of schooling on outcomes for ancestors. Children aged 30 and older

\begin{tabular}{|c|c|c|c|c|c|c|}
\hline & (1) & (2) & (3) & (4) & (5) & (6) \\
\hline & \multicolumn{6}{|c|}{ Panel A: Schooling } \\
\hline \multirow[t]{2}{*}{ Parents } & .345 & & .335 & & .334 & .332 \\
\hline & $(.006)$ & & $(.006)$ & & $(.006)$ & $(.006)$ \\
\hline \multirow[t]{2}{*}{ Grandparents } & & .164 & .045 & & .044 & .040 \\
\hline & & $(.008)$ & $(.008)$ & & $(.008)$ & $(.008)$ \\
\hline \multirow[t]{2}{*}{ Great grandparents } & & & & .085 & .034 & .027 \\
\hline & & & & $(.020)$ & $(.019)$ & $(.019)$ \\
\hline \multirow[t]{2}{*}{ Parents' aunts/uncles } & & & & & & .017 \\
\hline & & & & & & $(.005)$ \\
\hline \multirow[t]{2}{*}{ Sum of estimates } & .345 & .164 & .380 & .085 & .412 & .415 \\
\hline & $(.006)$ & $(.008)$ & $(.009)$ & $(.020)$ & $(.020)$ & $(.020)$ \\
\hline \multirow[t]{2}{*}{$R^{2}$} & .150 & .023 & .159 & .005 & .161 & .090 \\
\hline & \multicolumn{6}{|c|}{ Panel B: Schooling and income } \\
\hline \multirow[t]{2}{*}{ Parents } & .442 & & .430 & & .429 & .427 \\
\hline & $(.007)$ & & $(.007)$ & & $(.007)$ & $(.007)$ \\
\hline \multirow[t]{2}{*}{ Grandparents } & & .209 & .048 & & .047 & .042 \\
\hline & & $(.009)$ & $(.009)$ & & $(.009)$ & $(.010)$ \\
\hline \multirow[t]{2}{*}{ Great grandparents } & & & & .092 & .034 & .026 \\
\hline & & & & $(.021)$ & $(.020)$ & $(.020)$ \\
\hline \multirow[t]{2}{*}{ Parents' aunts/uncles } & & & & & & .020 \\
\hline & & & & & & $(.006)$ \\
\hline \multirow[t]{2}{*}{ Sum of estimates } & .442 & .209 & .478 & .092 & .510 & .514 \\
\hline & $(.007)$ & $(.009)$ & $(.010)$ & $(.021)$ & $(.021)$ & $(.022)$ \\
\hline \multirow[t]{2}{*}{$R^{2}$} & .105 & .026 & .108 & .005 & .108 & .109 \\
\hline & \multicolumn{6}{|c|}{ Panel C: Schooling, income, and social stratification } \\
\hline \multirow[t]{2}{*}{ Parents } & .466 & & .454 & & .453 & .451 \\
\hline & $(.007)$ & & $(.008)$ & & $(.008)$ & $(.008)$ \\
\hline \multirow{2}{*}{ Grandparents } & & .251 & .046 & & .046 & .041 \\
\hline & & $(.010)$ & $(.010)$ & & $(.011)$ & $(.011)$ \\
\hline \multirow[t]{2}{*}{ Great grandparents } & & & & .120 & .019 & .008 \\
\hline & & & & $(.031)$ & $(.029)$ & $(.029)$ \\
\hline \multirow[t]{2}{*}{ Parents' aunts/uncles } & & & & & & .019 \\
\hline & & & & & & $(.007)$ \\
\hline \multirow[t]{2}{*}{ Sum of estimates } & .466 & .251 & .500 & .120 & .517 & .518 \\
\hline & $(.007)$ & $(.010)$ & $(.011)$ & $(.031)$ & $(.030)$ & $(.030)$ \\
\hline$R^{2}$ & .109 & .028 & .112 & .005 & .112 & .113 \\
\hline$N$ & 41,309 & 41,309 & 41,309 & 41,309 & 41,309 & 41,309 \\
\hline
\end{tabular}

Note: The dependent variable is the child's years of schooling for those aged at least 30. Explanatory variables are average years of schooling, average lifetime incomes, and average social stratification measures for each type of relatives. Panels B and C show Lubotsky \& Wittenberg-type weighted sums, normalized to be comparable to the schooling coefficients. All regressions include linear and quadratic controls for average years of birth for each included type of relative. Robust standard errors in parentheses. 
Table A8h. Results from OLS regressions of the child's predicted years of schooling on ancestors' income. Children aged 30 and older

\begin{tabular}{lrrrrrr}
\hline & $(1)$ & $(2)$ & $(3)$ & $(4)$ & $(5)$ & $(6)$ \\
\hline Parents & .781 & & .750 & & .747 & .741 \\
& $(.021)$ & & $(.021)$ & & $(.021)$ & $(.021)$ \\
Grandparents & & .369 & .201 & & .202 & .191 \\
& & $(.025)$ & $(.024)$ & & $(.024)$ & $(.025)$ \\
Great grandparents & & & & .019 & .005 & -.000 \\
& & & & $(.019)$ & $(.018)$ & $(.018)$ \\
Parents' aunts/uncles & & & & & .095 \\
& & & & & $.021)$ \\
\hline Sum of estimates & .781 & .369 & .951 & .019 & .953 & 1.028 \\
& $(.021)$ & $(.025)$ & $(.029)$ & $(.019)$ & $(.034)$ & $(.038)$ \\
$R^{2}$ & .053 & .018 & .056 & .005 & .057 & .057 \\
$N$ & 41,309 & 41,309 & 41,309 & 41,309 & 41,309 & 41,309 \\
\hline
\end{tabular}

Note: The dependent variable is the child's years of schooling for those aged at least 30. Explanatory variables are average lifetime incomes for each type of relatives. The lower panel shows sums of coefficients. All regressions include linear and quadratic controls for average years of birth for each included type of relative. Robust standard errors in parentheses.

Table A8i. Results from OLS regressions of the child's predicted years of schooling on ancestors' occupational status index. Children aged 30 and older

\begin{tabular}{|c|c|c|c|c|c|c|}
\hline & (1) & (2) & (3) & (4) & (5) & (6) \\
\hline \multirow[t]{2}{*}{ Parents } & .045 & & .043 & & .042 & .042 \\
\hline & $(.001)$ & & $(.001)$ & & $(.001)$ & $(.001)$ \\
\hline \multirow[t]{2}{*}{ Grandparents } & & .028 & .014 & & .014 & .013 \\
\hline & & $(.001)$ & $(.001)$ & & $(.001)$ & $(.001)$ \\
\hline \multirow[t]{2}{*}{ Great grandparents } & & & & .003 & .000 & -.000 \\
\hline & & & & $(.002)$ & $(.001)$ & $(.001)$ \\
\hline \multirow[t]{2}{*}{ Parents' aunts/uncles } & & & & & & .004 \\
\hline & & & & & & $(.001)$ \\
\hline \multirow[t]{2}{*}{ Sum of estimates } & .045 & .028 & .057 & .003 & .057 & .060 \\
\hline & $(.001)$ & $(.001)$ & $(.002)$ & $(.002)$ & $(.002)$ & $(.002)$ \\
\hline$R^{2}$ & .056 & .022 & .060 & .005 & .061 & .061 \\
\hline$N$ & 41,309 & 41,309 & 41,309 & 41,309 & 41,309 & 41,309 \\
\hline
\end{tabular}

Note: The dependent variable is the child's years of schooling for those aged at least 30. Explanatory variables are average social stratification measures for each type of relatives. The lower panel shows sums of coefficients. All regressions include linear and quadratic controls for average years of birth for each included type of relative. Robust standard errors in parentheses. 
Table A9a. Results from OLS regressions of the child's predicted years of schooling ancestors' years of schooling. Only complete dynasties

\begin{tabular}{|c|c|c|c|c|c|c|}
\hline & $(1)$ & $(2)$ & (3) & $(4)$ & $(5)$ & (6) \\
\hline \multirow[t]{2}{*}{ Parents } & .208 & & .183 & & .182 & .176 \\
\hline & $(.003)$ & & $(.003)$ & & $(.003)$ & $(.003)$ \\
\hline \multirow[t]{2}{*}{ Grandparents } & & .104 & .043 & & .039 & .027 \\
\hline & & $(.003)$ & $(.003)$ & & $(.003)$ & $(.004)$ \\
\hline \multirow[t]{2}{*}{ Great grandparents } & & & & .137 & .029 & .012 \\
\hline & & & & $(.007)$ & $(.007)$ & $(.008)$ \\
\hline \multirow[t]{2}{*}{ Parents' aunts/uncles } & & & & & & .035 \\
\hline & & & & & & $(.004)$ \\
\hline \multirow[t]{2}{*}{ Sum of estimates } & .208 & & .226 & & .250 & .250 \\
\hline & (.003) & & $(.004)$ & & $(.007)$ & $(.007)$ \\
\hline$R^{2}$ & .123 & .082 & .132 & .059 & .133 & .136 \\
\hline$N$ & 52,701 & 52,701 & 52,701 & 52,701 & 52,701 & 52,701 \\
\hline
\end{tabular}

Note: The sample is restricted to only observations with non-missing schooling information for both parents, all four grandparents, and all eight great grandparents. The dependent variable is the child's years of schooling for those aged at least 30, and predicted years of schooling based on 9th grade GPA and high school track for those aged below 30. The explanatory variables are average years of schooling for each type of relatives. All regressions include linear and quadratic controls for average years of birth for each included type of relative. Robust standard errors in parentheses.

Table A9b. Results from OLS regressions of the child's predicted years of schooling on horisonally extended family years of schooling. Only complete dynasties

\begin{tabular}{|c|c|c|c|c|c|c|}
\hline & (1) & (2) & (3) & (4) & (5) & (6) \\
\hline \multirow[t]{2}{*}{ Parents } & .208 & .176 & .172 & .164 & .164 & .163 \\
\hline & $(.003)$ & $(.003)$ & $(.003)$ & $(.003)$ & $(.003)$ & $(.003)$ \\
\hline \multirow[t]{2}{*}{ Parents' siblings } & & .092 & .080 & .069 & .069 & .066 \\
\hline & & $(.004)$ & $(.004)$ & $(.004)$ & $(.004)$ & $(.004)$ \\
\hline \multirow[t]{2}{*}{ Spouses of aunts/uncles } & & & .032 & .027 & .027 & .021 \\
\hline & & & $(.004)$ & $(.004)$ & $(.004)$ & $(.004)$ \\
\hline \multirow[t]{2}{*}{ Parents' cousins } & & & & .087 & .078 & .077 \\
\hline & & & & $(.005)$ & $(.007)$ & $(.007)$ \\
\hline \multirow[t]{2}{*}{ Spouses of parents' cousins } & & & & & .017 & .016 \\
\hline & & & & & $(.006)$ & $(.006)$ \\
\hline \multirow[t]{2}{*}{ Siblings of spouses of aunts/uncles } & & & & & & .021 \\
\hline & & & & & & $(.004)$ \\
\hline \multirow[t]{2}{*}{ Sum of coefficients } & .208 & .268 & .284 & .348 & .354 & .364 \\
\hline & $(.003)$ & $(.004)$ & (.004) & $(.006)$ & (.006) & $(.006)$ \\
\hline$R^{2}$ & .123 & .133 & .135 & .140 & .140 & .140 \\
\hline$N$ & 52,701 & 52,701 & 52,701 & 52,701 & 52,701 & 52,701 \\
\hline
\end{tabular}

Note: The sample is restricted to only observations with non-missing schooling information for both parents, all four grandparents, and all eight great grandparents. The dependent variable is the child's years of schooling for those aged at least 30, and predicted years of schooling based on 9th grade GPA and high school track for those aged below 30. The explanatory variables are average years of schooling for each type of relatives. All regressions include linear and quadratic controls for average years of birth for each included type of relative. Robust standard errors in parentheses. 